\title{
Plato to Peter Higgs
}

\author{
*Dr.(Prof.) V.C.A. NAIR \\ Educational Physicist, Research Guide for Physics, Resource person in the area of Physics and \\ Distinguished Alumni of Shri J.J.T University, Rajasthan, India. \\ *nairvca39@gmail.com
}

\begin{abstract}
The contents of the paper is a historical and philosophical perspective of the development of Physics starting from the Classical Greece Period and ending with the present days of the current century. Some eighty scientists randomly chosen and who have contributed to the development with a brief account of their work are included. There is an extensive treatment on Higgs boson. As a picture speaks thousand words, picture of each scientist is given at appropriate places. Hence, pictures and brief description of scientists form the main contents of the paper. From this point of view, the style of the paper differs from usual Research Methodology but, it will certainly be useful (I hope) for a physicist working on the history and philosophy of Physics.
\end{abstract}

Keywords: The contents being mainly pictures of scientists and their work, the key words are many and hence the same is not included

\section{INTRODUCTION}

1.1 Then and Now: The paper is something like "What was 'then' and what is 'now'? We want to see the 'beginning' and also 'beyond'. I have extensively gone through a book titled, "Q is for Quantum, an encyclopedia of Particle Physics" by John Gribbin and published in 1998 by Simon \& Schuster, New York. It is not only a popular book but a treatise in its own style. John Gribbin has dealt not only with the subject matter but also with the scientists and authors in that book in alphabetical order whereas, in letter and spirit of the title of my paper, I have dealt with the matter in a chronological order starting from Classical Greece period and ending with the $20^{\text {th }}$ century. Earlier I thought of keeping the title as 'E' for 'Einstein' or 'Aristotle to Einstein', but then more than six decades have passed after the death of Einstein in 1955 and the research in Physics after 1955 was in leaps and bounds. Hence, I thought of a recent discovery (in 2012) at the Large Hadron Collider (LHC) at Geneva of the God's particle by Peter Higgs which brought him a Nobel Prize in 2013 and world acclaim. Peter Higgs and Albert Einstein even though are not comparable, the very idea is to include an eminent physicist of today and Peter Higgs is still alive. To sum up the entire contents of the paper is just history, philosophy and development of Physics.

\subsection{The European Periods:}

1. The Classical Greece $(480$ BC -399 BC)

2. Macedonian Era (399 BC - 323 BC)

3. Hellenistic Greece $(323 \mathrm{BC}-146 \mathrm{BC})$

4. Late Roman Republic (146 BC - 27 BC)

5. Principate of the Roman Empire (27 BC - 284 AD)

6. Late Antiquity (284 $\mathrm{AD}-500 \mathrm{AD}$ and beyond)

We shall consider maximum, if not all, number of scientists which in some cases may be just one or two from each period and give a brief description of the scientist with his picture. In order to strictly follow the time periods as mentioned above, we start with Socrates (480 BC - $399 \mathrm{BC}$ ). What appears next is Plato (428/427 BC - 348/347 BC). Even though there is a brief description of Plato appearing there, to start with, we may give little more details of Plato, the philosopher scientist and teacher of Aristotle.

\section{PLATO}

2.1 Plato and his Mathematics: Although usually remembered today as a philosopher, Plato (Fig.1)was also one of ancient Greece's most important patrons of mathematics. Inspired by Pythagoras, he founded his Academy in Athens in 387 BCE, where he stressed mathematics as a way of understanding more about reality. In particular, he was convinced that geometry was the key to unlocking the secrets of the universe. The sign above the Academy entrance read: "Let no-one ignorant of geometry enter here". 
Plato played an important role in encouraging and inspiring Greek intellectuals to study mathematics as well as philosophy. His Academy taught mathematics as a branch of philosophy, as Pythagoras had done, and the first 10 years of the 15 year course at the Academy involved the study of science and mathematics, including plane and solid geometry, astronomy and harmonics. Plato became known as the "maker of mathematicians", and his Academy boasted some of the most prominent mathematicians of the ancient world, including Eudoxus, Theaetetus and Archytas.

He demanded of his students accurate definitions, clearly stated assumptions, and logical deductive proof, and he insisted that geometric proofs be demonstrated with no aids other than a straight edge and a compass. Among the many mathematical problems Plato posed for his students' investigation were the so-called Three Classical Problems ("squaring the circle", "doubling the cube" and "trisecting the angle") and to some extent these problems have become identified with Plato, although he was not the first to pose them.

2.2 Plato's Geometry: Plato the mathematician is perhaps best known for his identification of 5 regular symmetrical 3-dimensional shapes, which he

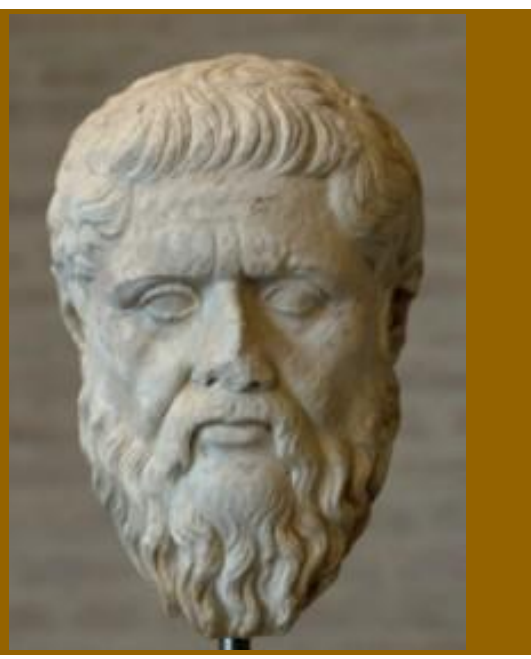

Fig.1 Plato (428/427 - 348/347) $(424 / 423$ maintained were the basis for the whole universe, and which have become known as the Platonic Solids (Fig.2) the tetrahedron (constructed of 4 regular triangles, and which for Plato represented fire), the octahedron (composed of 8 triangles, representing air), the icosahedron (composed of 20 triangles, and representing water), the cube (composed of 6 squares, and representing earth), and the dodecahedron (made up of 12 pentagons, which Plato obscurely described as "the god used for arranging the constellations on the whole heaven"). The tetrahedron, cube and dodecahedron were probably familiar to Pythagoras, and the octahedron and icosahedron were probably discovered by Theaetetus, a contemporary of Plato. Furthermore, it fell to Euclid, half a century later, to prove that these were the only possible convex regular polyhedra. But they nevertheless became popularly known as the Platonic Solids, and inspired mathematicians and geometers for many centuries to come.

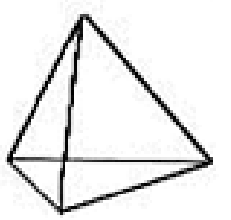

Tetrahedron

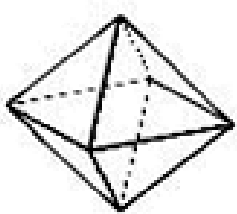

Octahedron

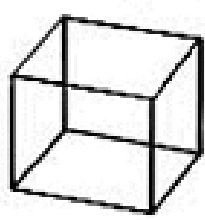

Cube

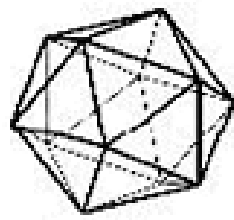

Icosahedron

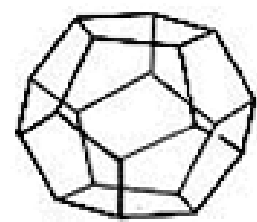

Dodecahedron

Fig.2 Platonic Solids For example, around 1600, the German astronomer Johannes Kepler devised an ingenious system of nested Platonic solids and spheres to approximate quite well the distances of the known planets from the Sun (although he was enough of a scientist to abandon his elegant model when it proved to be not accurate enough).

\section{BRIEF DESCRIPTION OF SCIENTISTS AND THEIR WORK}

3.1 Preamble: Even though the title is "Plato to Peter Higgs", we include one or two scientists prior to Plato and after Higgs. The matter given regarding each scientist should not be taken merely as a biography, but the reader should focus on the scientific work done by the scientist in the development of Physics. The various scientists are:

\section{Some of the Creators of PHYSICS \\ Note: The Figures of the Pictures are not numbered Classical Greece (480 BC - 399 BC)}

\section{Socrates} (470 BC - 399 BC)

Socrates was a classical Greek philosopher credited as one

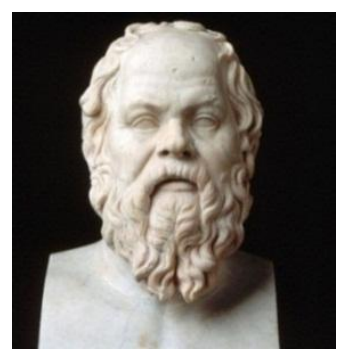

ethical tradition of thought. The ground work for western systems of logic and philosophy is based on what is known as "Socratic Method". One of his famous students was Plato. of the founders of western philosophy and as being the first moral philosopher of the western 


\section{International Advanced Research Journal in Science, Engineering and Technology}

Vol. 5, Issue 8, August 2018

2 Plato

(428/427 BC - 348/347 BC)

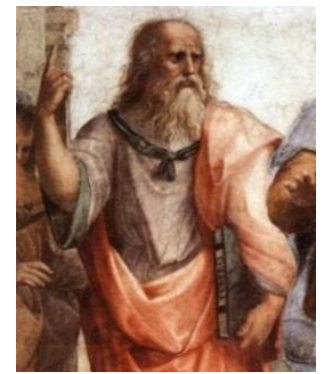

Plato was a Greek philosopher and student of Socrates was born in

Athens. His real name was

Aristocles because of his broad shoulders, he is given a nick name 'Plato' meaning 'Broad' in Greek. He wrote many articles in politics, ethics, metaphysics and epistemology. His major work is the 'Dialogues' which helped for politics, democrazy, monarchy and aristocrazy. At the portals of his academy in Athens reads a legend:"Let no one presume to enter here unless he has a taste for Geometry"

\section{Macedonian Era (399 BC -323 BC)}

\section{Aristotle}

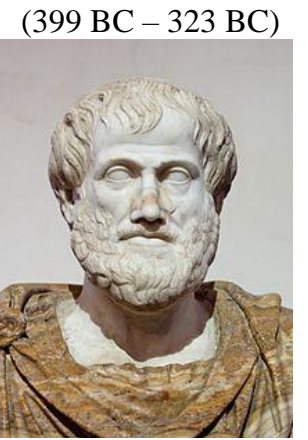

Aristotle was a Greek philosopher scientist who studied under Plato

(Fig.2). He believed that everything in the universe moved harmoniously around the Earth. He wrote the first known book, titled "Physics" which consisted a set of 8 books that was a detailed study of motion and its causes. A Greek translation of the book is known as "Natural Philosophy". Aristotle vigorously contested the corpuscular theory of light. On

Magnetsm, he said: "Magnet has a soul as it causes movement to iron". He had entered the fields of logic, metaphysics, politics, Physics, mathematics, astronomy and even Biology in which he is sometimes called "Father of modern anatomy".

\section{Hellenistic Greece (323 BC - 146 BC)}

4 Archimedes $(287-212 \mathrm{BC})$

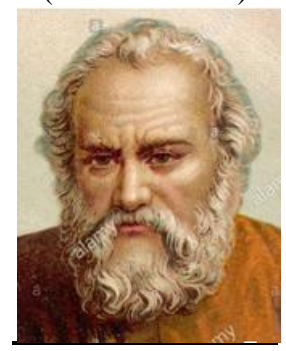

Archimedes of Syracuse was a Greek mathematician, physicist, engineer, inventor and astronomer. Although few details of his life are known, he is famous for his Archimedes principle, Archimedes' screw, Siege of Syracuse, Claw of Archimedes and the famous legend, "Eureka" meaning "I have found it". He advanced the studies of Geometry of "Eudoxus" and found the exact value of $\mathrm{Pi}(\pi)$.

\section{Hipparchus} $(225-160 \mathrm{BC})$

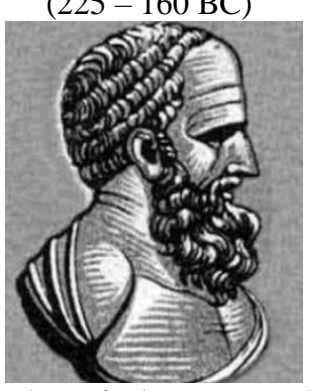

Hipparchus of Nicaea was a Greek astronomer, geographer and mathematician. He is considered as one of the originators of Physics who made it into a 'Physical

Science' Hipparchus is known as the founder of modern

Trigonometry and famous for his incidental discovery of precession of the equinoxes.

\section{Late Roman Republic (147 BC - 27 BC)}

\section{MarcusVitruviusPollio}

(80/70BC-15BC) Marcus Vitruvius Pollio,

commonly known as Vitruvius,

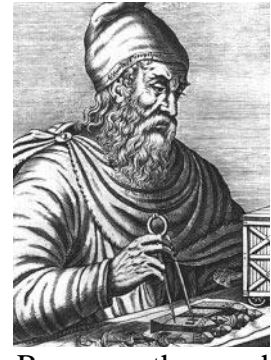

was a Roman author, architect,

civil engineer and military engineer during the 1 st century $\mathrm{BC}$, known for his multi-volume work entitled De architectura

\section{Principate of the Roman Empire}

(27 BC - 284 7AD)

Ptolemy

(100-170 AD)

Ptolemy was a Greek philosopher who wrote the 'Almagest', a 13 volume description of the universe at his time. The ptolemic system was followed for nearly 1000 years since then. He contributed to

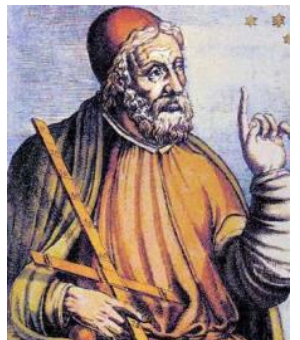

Refraction of Light. Here is a saying from him in Latin"cursus naturae in conservandis actibus, virtutis" the meaning of which is, "running the preservation of nature activities with might"

\section{Late Antiquity \\ (284AD-500AD and after) $10^{\text {th }}$ Century (901-1000)}

\section{Alhazen \\ (965 - $1040 \mathrm{AD}$}

An Arab born in Basra, Iraq is taken as the originator of the "Scientific Method". Much before Isaac Newton. Al Hazen's books on Optics had a greater effect on western thought. He even corrected

Ptolemy in the investigation of properties of

light specially on refraction regarding which he said:"Angles 


\section{International Advanced Research Journal in Science, Engineering and Technology}

Vol. 5, Issue 8, August 2018

the Scholastic method of university teaching. He is remembered today largely for his book De Magnete (1600), and is credited as one of the originators of the term "electricity". He is regarded by some as father of electricity and magnetism.

of refraction do not follow the same proportion as the angles of incidence, but these proportions differ in the same transparent body"

\section{$15^{\text {th }}$ Century (1401-1500)}

\section{CopernicusNicolaus} (1473-1543)

Cpernicus was Polish astronomer first to publish a book arguing that the solar system is a heliocentric (Sun-centered) system instead of geocentric (Earth-cenetered) system. He published a book on the

"Revolutions of the Celestial

System". He had some idea of universal gravitation akin to that of

Newton.. He wrote that the

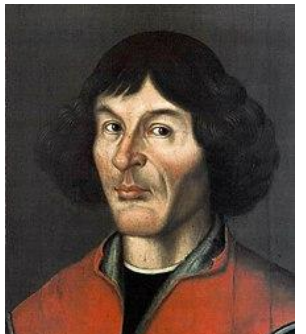

"State of immobility is regarded as more noble and God-like than that of change and instability, which for that reason should belong to the Earth rather than to the Universe"

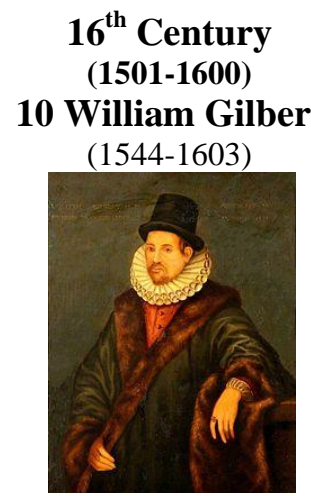

William Gilbert, also

known as Gilberd, was an English physician, physicist and natural philosopher. He passionately rejected both the prevailing Aristotelian philosophy and

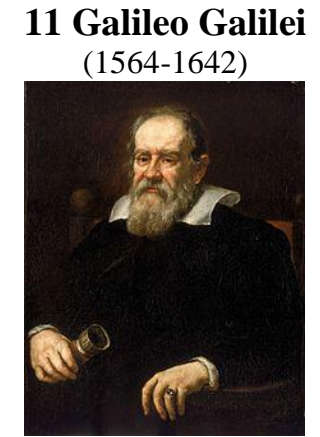

Galileo was an Italian scientist, mathematician and astronomer born in Pisa, Italy. Studied at Vailombrosa, Monastery near Florence. Studied Mathematics at the university of Pisa and started teaching at the university of Padua. He was the first to prove that the

Sun is the center of the solar system. He made astronomical telescopes and studied craters of the Moon.

Galileo is famous for some of the thought experiments he performed from the leaning tower of Pisa. The

'Starry Messenger' published by him was very exciting.

\section{Johannes Kepler} (1571-1630)

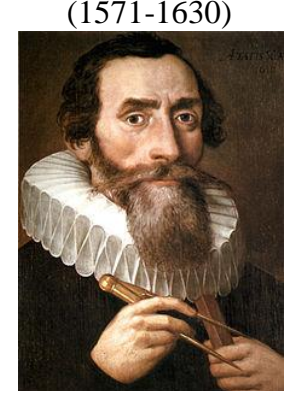

Kepler, Well-known for his laws of planetary motion. He studied the orbit of Mars and proved that it is an ellipse. He did research in Optics and in 1604 published his first book on Optics titled,

"Dioptrice". He studied 'Total Reflection' and passage of light through lenses of various shapes. It is he who said the human eye is like a Camera. He also made telescopes.
13 Rene Descartes du Perron (1596-1650)

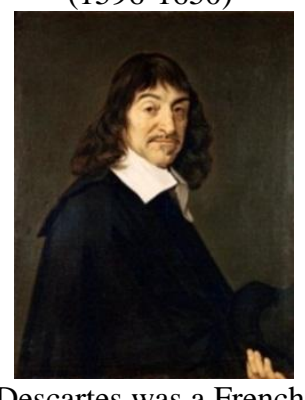

Descartes was a French philosopher, mathematician and physicist. Famous for the 'Cartesian Systen' described by him in 1637 in his work named,

'La Geometrie' 'Using lunar eclipse. He proved that the speed of light was not infinite. He explained the formation of

rainbow with the help of Snell's law of refraction.

Even before Newton, he had idea of the first law and the law of gravitation. There is the Des

Carte's atomism wherein mentioned that he was quite willing to commit himself

irrevocably to the faith that all matter was resolvable into atoms, to the interrelations of which all natural phenomena are due. In his

famous 'Vortex theory', he imagined a complete system of nature in which everything from stars and stones to living bodies was reduced to a combination of

material particles, moving according to mathematical laws. He said: "Give me Matter and Motion and I will construct the Universe"

$$
\begin{gathered}
\text { 17 }^{\text {th }} \text { Century } \\
\text { (1601-1700) }
\end{gathered}
$$

\section{Blaise Pascal} (1623-1662)

Blaise Pascal was a French mathematician, physicist, inventor, writer and Catholic theologian.

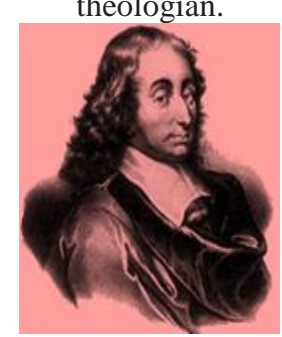




\section{International Advanced Research Journal in Science, Engineering and Technology}

Vol. 5, Issue 8, August 2018

He was a child prodigy famous for the 'Pascal's Law' regarding pressure of fluids and the unit,

'Pascal' for pressure is assigned in his memory.

\section{Robert Boyle (1627-1691)}

Robert Boyle, an Irish chemist and philosopher known as the father of Chemistry and famous for Boyle's law according to which a certain volume of gas held at constant

temperature is inversely proportional to its pressure. $\mathrm{He}$ designed the Bell-Jar experiment to show that a material medium is necessary for the propagation of sound. He improved the air pump invented by Von Guericke.. In

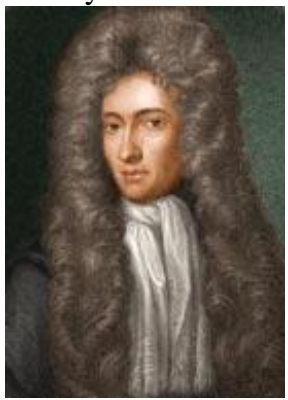

1661 he disputed the nature of four elements and argued that the true elements can neither be decomposed nor be formed from other materials.

\section{Sir Isaac Newton} (1642-1727)

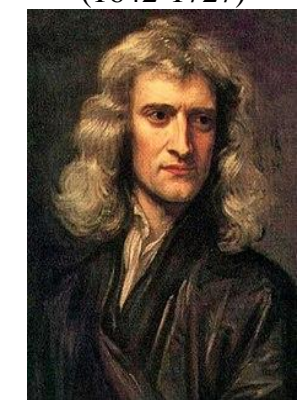

Isaac Newton, the English Physicist and

born on Christmas Day 1642 at Woolsthorpe in Lincolnshire. He laid the foundation for modern Science with his Laws of Motion and theory of gravity. Made important contributions in Optics and invented 'Calculus'. $\mathrm{He}$ is considered as the greatest scientist who ever lived for his discoveries and the techniques for experiment and observation. His greatest work known as 'Principia' which was

published in 1687. According to Newton, the laws of Physics are universal and what we use today for the study of Big Bang or the study of quarks, the laws used by him still holds. The unit, 'Newton' is assigned for 'Force' in his honor.

\section{Daniel Bernoulli} (1700-1782)

Bernoulli, a Swiss physicist and mathematician famous for the principle named after him. Bernoulli found that the speed of water flowing through a tube

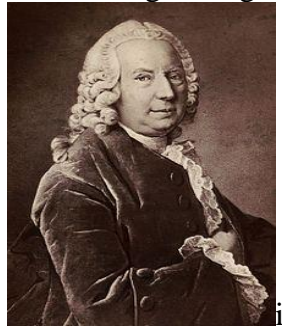

increased with decrease in diameter of the tube. This is known as the 'Continuity principle'. With this as the basis, he noticed that the pressure exerted by the water on the walls of the tube was less as well. This discovery known as the 'Bernoulli's principle' is very important in the study of Fluid Mechanics'. Daniel Bernoulli and his father, Johann Bernoulli were declared joint winners of a grand prize in astronomy given by the Paris Academy of Sciences.

\section{$18^{\text {th }}$ Century (1701-1800)}

\section{Henry Cavendish}

$$
\text { (1731-1810) }
$$

physicist born in Nice, France famous for the Cavendish experiment with which he confirmed Newton's law of

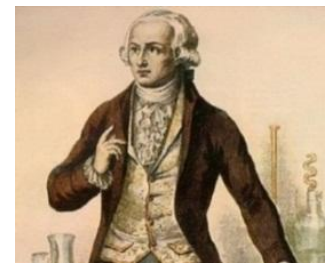

gravitation and found the value of constant of gravitation. In 1798, he found the average density of the Earth and also concluded that the center of the Earth must contain very dense heavy metals. He discovered Hydrogen and received the Copley Medal in 1766. He also found out that water is a compound

of Oxygen and Hydrogen. It is

Henry who coined the terms:

'intensity' and 'quantity' of current. At one place (summarizing many experiments on Induction), he says: 'an intensity current can induce one of quantity and..... a quantity current can induce one of

intensity' The unit of self inductance, 'Hentry' is named after him

\section{James Watt}

(1736-1819)

James Watt, a Scottish enginer, inventor and instrument maker in the University of Glasgow and on whom the SI unit of Horse Power (HP) and power, 'Watt' is given, is an outstanding scientist. He found

that an average healthy horse

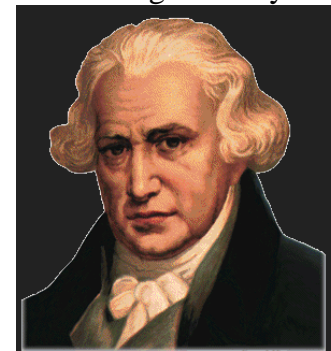

can draw 150 pounds of coal from

a mine 220 feet deep in one minute. From this he arrived at the idea of Horse Power (HP) the value of which is 746 Watt. The inventor of the present steam engine actually did it in 1863 during the process of repair of a 'Fire Engine', the name for fire engine those days. He devised instrument called steam engine indicator which would record just such diagrams for engines in actual operation. Such diagrams, known as 'indicator diagrams' developed by him are of immense use for engineers even today. Probably the most important technical advancement of the eighteenth century and one that may be truly said to have ushered a new era of industrial development started with James Watt. It was more of a technological than a scientific advance. 


\section{International Advanced Research Journal in Science, Engineering and Technology}

Vol. 5, Issue 8, August 2018

\section{Galvani Luigi}

(1737-1798)

Galvani, an Italian physician in the University of Bologna discovered in 1791 what is known as 'Galvanism' during the dissection of a frog. The frog was kept in some chemical in a tray of certain metal to which

was attached a knife of

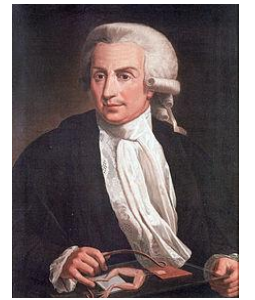

some other metal. Whenever the knife touched the body of the frog, it gave a convulsive motion. $\mathrm{He}$ repeated the experiment with many frogs and saw the same phenomenon and believed that some current was flowing through the body of the frog and called it" Animal electricity'. This phenomenon led to the discovery of 'current electricity'.

The Galvanism remained till

Galvani's fellow countryman,

Alessandro Volta from the University of Pavia rejected the concept of 'Animal Electricity' and argued that: "Two different metals in the presence of a chemical will develop potential difference responsible for the current and the body of the animal simply served as a conductor",

A current detecting instrument ,'Galvanometer' and

'Galvanizing' in industry are names given to honor Galvani.

\section{Alessandro Volta} (1745-1827)

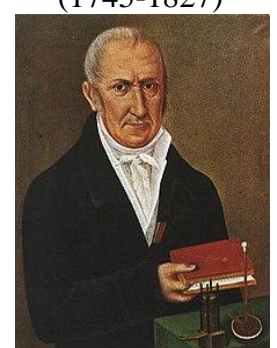

Alessandro Giuseppe Antonio Anastasio Volta was an Italian physicist, chemist, and a pioneer credited as the inventor of the electrical battery in 1800 and the discoverer of methane. It was Volta who made the electrical battery in 1800 and also the discoverer of methane. It was he who asserted that the galvanic current was not Animal Electricity but due to the development of a potential difference. He found that two metals which produced greatest electrical effect was zinc and silver. He stacked alternating discs of zinc and silver separated by a card dipped in salt water to form a pile known as 'Volta's Pile' and with large number of such pairs he could get enormous current. The term 'electromotive force (emf)' is very much due to Volta and his name is abbreviated to 'Volt' as a unit for both potential difference and emf.

\section{Pierre-Simon Laplace}

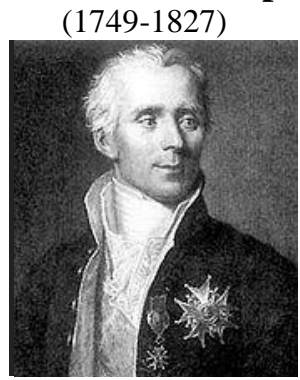

Pierre-Simon, marquis de Laplace was a French scholar whose work was important to the development of mathematics statistics, physics and astronomy. He summarised and extended the work of his predecessors in his five-volume

'Mécanique Céleste' Laplace formulated Laplace's equation , and pioneered the Laplace transform which appears in many branches of mathematical physics, a field that he took a leading role in forming. the Laplacian differential operator, widely used in mathematics, is also named after him. He restated and developed the nebular hypothesis of the origin of the Solar

System and was one of the first scientists to postulate the existence of black holes and the notion of gravitational collapse He explained Tides with the help of his Tidal Equations.

\section{Benjamin Thompson (1753-1814)}

Sir Benjamin Thompson, Count Rumford, FRS was an American- born British physicist and inventor whose challenges to established

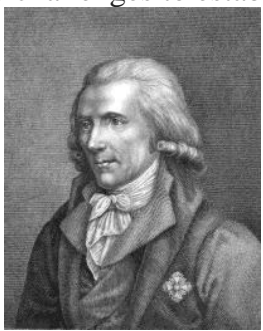

physical theory were part of the

19th century revolution in thermodynamics .Before Joule He was the pioneer to deal with the concept of 'Mechanical Equivalent of Hea

\section{John Dalton} (1766-1844)

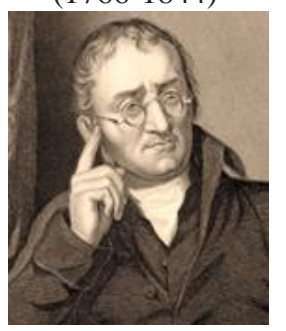

John Dalton was an English chemist, physicist, and meteorologist. He is best known for introducing the atomic theory into chemistry in 1808 and 1810 , and for his research into colour blindness, sometimes referred to as Daltonism in his honour. $\mathrm{He}$ is the first scientist to say that atoms combine to form compounds and separated Chemistry from Physics.

\section{Joseph Fourier (1768-1830)}

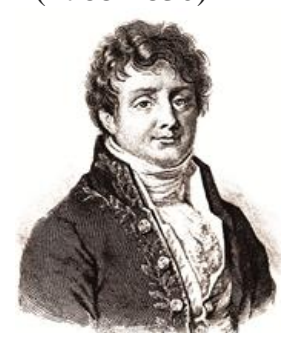

Fourier, a French

mathematician and physicist born in Auxerre and best known for initiating the investigation of

Fourier series and their applications to problems of heat transfer and vibrations. The Fourie transform and Fourier's law are also named in his honor. Fourier is also generally credited with the discovery of the greenhouse effect 


\section{International Advanced Research Journal in Science, Engineering and Technology}

Vol. 5, Issue 8, August 2018

26. Thomas Young (1773-1829)

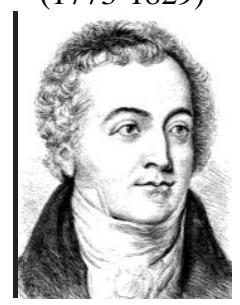

Thomas Young was a British polymath, physicist and physician. Young made notable scientific contributions to the fields of vision, light, solid mechanics, energy, physiology language, musical harmony, and Egyptology. He "made a number of original and insightful innovations in the decipherment of Egyptian hieroglyphs (specifically the Rosetta Stone) before JeanFrançois Champollion eventually expanded on his work. It is Young who introduced the term, 'Energy' in Physics. He was a versatile genius who introduced the term, mentioned by, among

'Accommodation' (Focusing) and 'Astigmatism' of the human eye.

Among others, William

Herschel, Hermann von

Helmholtz, Clerk Maxwell and Albert Einstein. Young has been described as "The Last Man

Who Knew Everything"

\section{Avogadro}

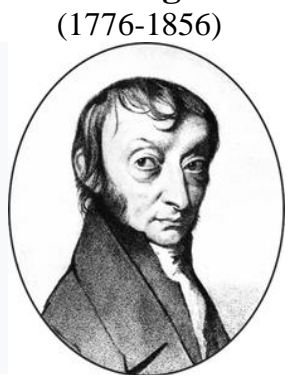

Amedeo Carlo Avogadro, was an Italian scientist, most noted for his contribution to molecular theory now known as Avogadro's law, which states that equal volumes of gases under the same conditions of temperature and pressure will contain equal numbers of molecules. In tribute to him, the number of elementary entities (atoms, molecules, ions or other particles) in 1 mole of a substance, $6.022140857(74) \times 10^{23}$, is known as the Avogadro constant, one of the seven SI base units and represented by $N_{\mathrm{A}}$.

\section{Georg Simon Ohm}

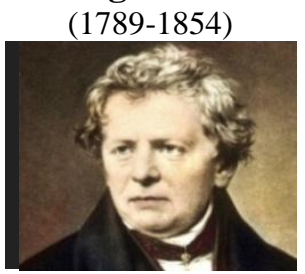

Georg Simon Ohm was a German physicist and mathematician. As a school teacher, Ohm began his research with the new electrochemical

cell, invented by Italian scientist Alessandro Volta. He found out that the flow of current in a conductor is due the potential difference developed at the ends of the conductors. When there is no change in the physical state of a conductor, the ratio of potential difference and current is a constant named after him as the unit Ohm.

\section{Michael Faraday} (1791-1867)

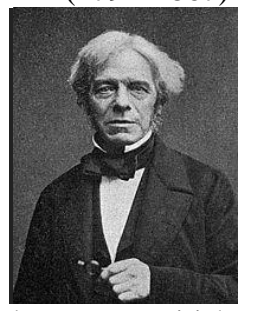

Faraday was a British scientist who contributed to the study of electromagnetism and

electrochemistry. In 1831, Faraday discovered electromagnetic induction, the principle behind the electric transformer and generator.

This discovery was crucial in allowing electricity to be transformed from a curiosity into a powerful new technology

\section{Sadi Carnot}

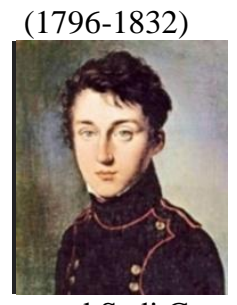

Nicolas Leonard Sadi Carnot was a French military engineer and physicist, often described as the "father of thermodynamics" and famous for the term, 'Heat Engine'. Like Copernicus, he published only one book, the Reflections on the Motive

Power of Fire(Paris, 1824), in

which he expressed, at

the age of 27 years, the first successful theory of the maximum efficiency of heat engines. $\mathrm{He}$ asserted that difference in temperature was the cause for

'Motive Power' In this work he laid the foundations of an entirely new discipline, thermodynamics.

\section{Joseph Henry} (1797-1878)

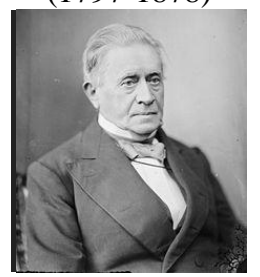

Henry was an American scientist who served as the first Secretary of the Smithsonian Institution. He was the secretary for the National Institute for the Promotion of

Science, a precursor of the Smithsonian Institution. He was highly regarded during his lifetime.

While building electromagnets, Henry discovered the electromagnetic phenomenon of self-inductance. He also

discovered mutual inductance independently of Michael Faraday, though Faraday was the first to make the discovery and publish his results. Henry developed the electromagnet into a practical device. He invented a precursor to the electric doorbell (specifically a bell that could be rung at a distance via an electric wire, 1831) and electric relay (1835). The SI unit of inductance, the henry, is named in his honor.

\section{$19^{\text {th }}$ Century \\ (1801-1900) \\ 32.William}

Rowan Hamilton

(1805-1865)

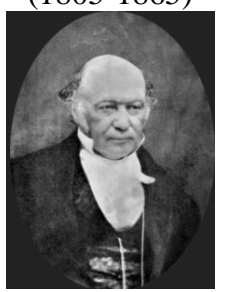




\section{International Advanced Research Journal in Science, Engineering and Technology}

Vol. 5, Issue 8, August 2018

transformations were first published in 1843 .

34. Gustav Kirchhoff was an Irish mathematician who made important contributions to classical mechanics, optics, and algebra. Although Hamilton was not a physicist-he regarded himself as a pure mathematicianhis work was of major importance and algebra to physics, particularly his reformulation of Newtonian mechanics, now

called Hamiltonian mechanics.

This work has proven central to the modern study of classical field theories such as electromagnetism, and to the development of quantum mechanics. In pure mathematics, he is best known as the inventor of quaternions.

William Rowan Hamilton's scientific career included the study of geometrical optics, classical mechanics, adaptation of dynamic methods in optical systems, applying quaternion and vector methods to problems in mechanics

\section{James Prescott Joule}

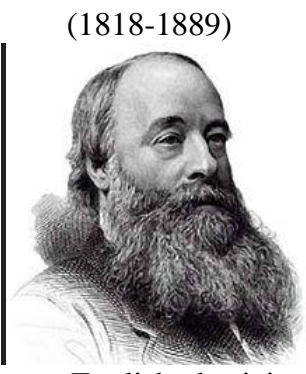

JoulewasanEnglish physicist, math ematiciann and brewer,Salford, $\mathrm{La}$ ncashire. Joule studied the nature of heat, and discovered its relationship to mechanical work . This led to the law of conservation of energy, which in turn led to the development of the first law of thermodynamics. The SI derived unit of energy, the joule, is named after him. Joule worked with Lord

Kelvin to develop an absolute thermodynamic temperature scale, which came to be called the Kelvin scale. Joule also made observations of magnetostriction, and he found the relationship

between the current through a resistor and the heat dissipated, which is also called Joule's first law. His experiments about energy (1824-1887)

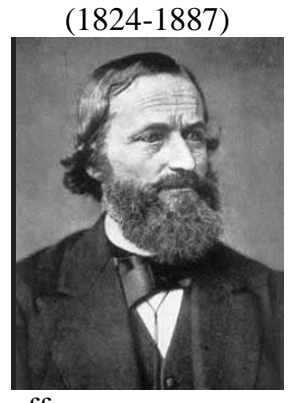

Kirchhoff was a German physicist who contributed to the fundamental understanding of electrical circuits, spectroscopy, and the emission of blackbody radiation by heated objects. $\mathrm{He}$ coined the term black-body radiation in 1862, and at least two different sets of concepts are named "Kirchhoff's laws" after him. The Bunsen-Kirchhoff Award for spectroscopy is named after him and his colleague, Robert Bunsen

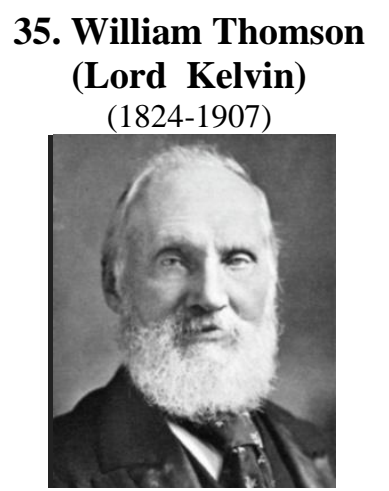

William Thomson who later on known as Lord Kelvin was a ScotsIrish mathematical

physicist and engineer who was

born in Belfast in 1824. At

the University of Glasgow he did important work in

the mathematical analysis of electricity and formulation of the first and second laws of thermodynamics, and did much to unify the emerging discipline of physics in its modern form. He worked closely with mathematics professor Hugh Blackburn in his work. He also had a career as an electric telegraph engineer and inventor, which propelled him into the public eye and ensured his wealth, fame and honour. For his work on the transatlantic telegraph project he was knighted in 1866 by Queen Victoria, becoming Sir William Thomson. He had extensive maritime interests and was most noted for his work on the mariner's compass, which had previously been limited in reliability. Among the many names suggested in his honor, he chose the name 'Kelvin' which is the name of a river adjacent to the university of Glasgow.

Absolute temperatures are stated in units of kelvin in his honour. While the existence of a lower limit to temperature (absolute zero) was known prior to his work, Lord Kelvin is widely known for determining its correct value as approximately

-273.15 degree Celsius or -459.67

degree Fahrenheit. It is Lord Kelvin who coined the term, 'Kinetic Energy' for energy possessed by moving bodies.

\section{James Clerk Maxwell} (1831-1879)

Maxwell was a Scottish scientist in the field of mathematical physics His most notable achievement was to formulate the classical theory of electromagnetic radiation, bringing together for the first time electricity, magnetism, and light as different manifestations of the same phenomenon. Maxwell's equations for electromagnetism

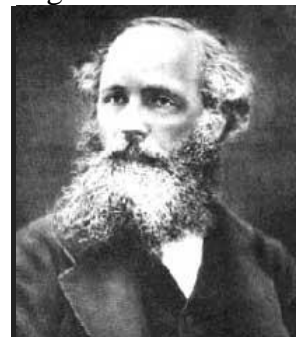

have been called the "second great unification in physics" after the first one realised by Isaac Newton. Author of "Treatise on Electricity and Magnetism" and the first head of the Cavendish Laboratory at the University of Cambridge. Maxwell proposed that light is an undulation in the same medium that is the cause of electric and magnetic phenomena. The unification of light and electrical 


\section{International Advanced Research Journal in Science, Engineering and Technology}

Vol. 5, Issue 8, August 2018

phenomena led to the prediction of the existence of radio waves.

Maxwell helped to develop the Maxwell-Boltzmann distribution, a statistical means of describing aspects of the kinetic theory of gases

\section{Dmitri Mendeleev} (1834-1907)

Mendeleev was a

Russian chemist and inventor. He formulated the Periodic Law, created a farsighted version of the periodic table of elements, and used it to correct the properties of

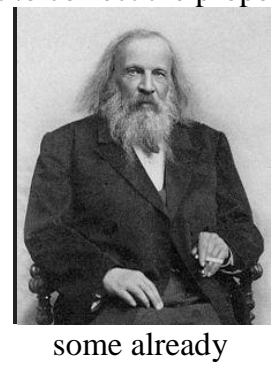

discovered elements and also to predict the properties of eight elements yet to be discovered at his time.

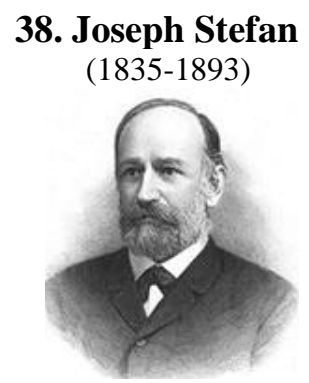

Stefan was an ethnic Carinthian Slovene physicist, mathematician, and poet of the Austrian Empire. He was one of the pioneers in the laws of radiation in which he collaborated with Boltzmann and said that the energy flux from a black body is proportional to the fourth power of the absolute temperature.

\section{Lord Rayleigh}

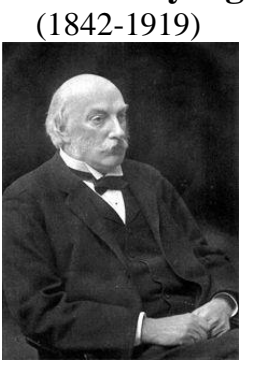

Lord Rayleigh was a physicist who, with William Ramsay, discovered argon, an achievement for which he earned the Nobel Prize for Physics in 1904. He also discovered the phenomenon now called Rayleigh scattering, which can be used to explain why the sky is blue, and predicted the existence of the surface waves now known as Rayleigh waves. Rayleigh's textbook, The Theory of Sound, is still referred to by acoustic engineers today.

\section{Ludwig Bltzmann} (1844-1906)

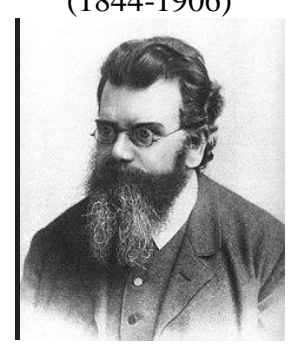

Boltzmann was an Austrian physicist who in 1877 introduced the concept of 'Entropy' and said that the temperature and energy of atoms can be co-related and the 'Entropy' of a system is a function of the 'probability' of its state. philosopher whose greatest achievement was in the development of statistical mechanics, which explains and predicts how the properties of atoms (such as mass, charge, and structure) determine the physical properties of matter (such as viscosity, thermal conductivity, and diffusion). Boltzmann coined the term 'energy' while he was working on a problem in statistical mechanics

\section{Wilhelm Rontgen} (1845-1923)

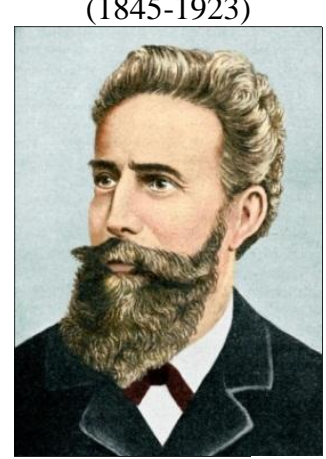

Rontgen was a German mechanical engineer and physicist, who, on 8 November 1895 , producedanddetected electromagne ticradiation ina wavelength range known as X-rays or Röntgen rays, an achievement that earned him the first Nobel Prize in Physics in 1901. In honour of his accomplishments, in 2004the International Union of Pure and Applied

Chemistry (IUPAC) named elemen t 111 , roentgenium, a radioactive element with multiple unstable isotopes, after him.

\section{Alexander Graham Bell} (1847-1922).

Alexander Graham Bell was a Scottish-born scientist, inventor, engineer, and innovator who is

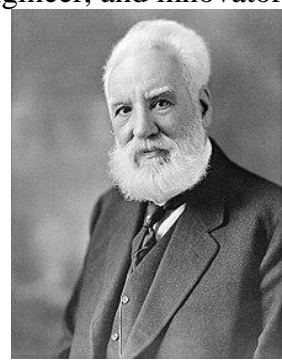

credited with inventing and patenting the first practical telephone

He also founded the American

Telephone and Telegraph

Company (AT\&T) in 1885

\section{Thomas Alva Edison} (1847-1931)

Edison was an American inventor and businessman, who

has been described as America's greatest inventor. . He developed many devices that greatly

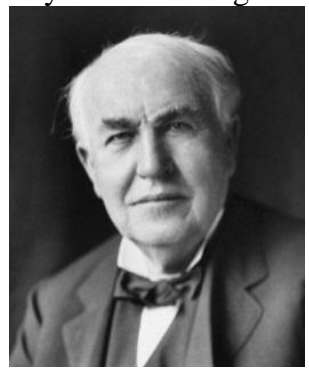

influenced life around the world, including the phonograph, the motion picture camera, and the long-lasting, practical electric light bulb. Dubbed "The Wizard of

Menlo Park", he was one of the first inventors to apply the principles of mass production and large-scale teamwork to the 


\section{International Advanced Research Journal in Science, Engineering and Technology}

Vol. 5, Issue 8, August 2018

process of invention, and is often credited with the creation of the

first industrial research laboratory. Edison was a prolific inventor, holding 1,093 US patents in his name, as well as many patents in the United Kingdom, France, and Germany. More significant than the number of Edison's patents was the widespread impact of his inventions: electric light and power utilities, sound recording, and motion pictures all established major new industries worldwide. Edison's inventions contributed to mass communication and, in particular, telecommunications.

\section{Michelson Albert} Abraham (1852-1931)

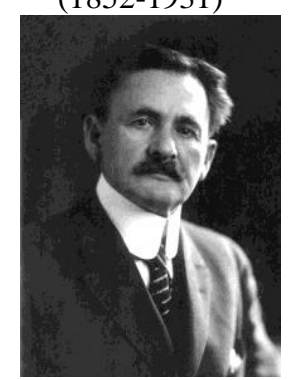

A. Michelson was a German born American physicist known for his work on measuring the speed of light and especially for the Michelson-Morley experiment. In 1907 he received the Nobel Prize in Physics, becoming the first American to win the Nobel Prize in a science. The results of the experiment laid the foundation for Einstein's General Theory of Relativity.

\section{Heike Kammerlingh} Onnes (1853-1926)

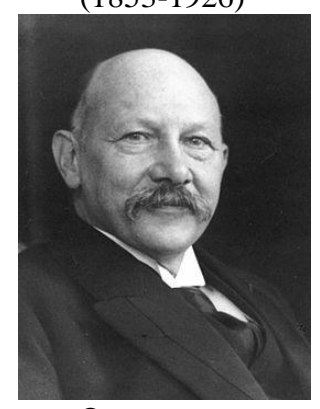

Onnes was a

Dutch physicist and Nobel laureate. He exploited the Hampson-Linde cycle to investigate how materials behave

when cooled to nearly absolute zero and later to liquefy helium for the first time, in 1908. He was also the discoverer of superconductivity in 1911

\section{Hendrik Lorentz} (1853-1928)

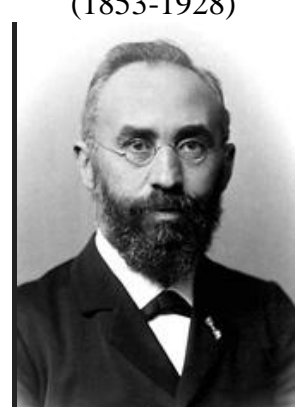

Lorentz was a Dutch physicist who shared the 1902 Nobel Prize in

Physics with Pieter Zeeman for the discovery and theoretical explanation of the Zeeman effect. $\mathrm{He}$ also derived the transformation equations of Albert Einstein's theory of Special Relativity. According to the biography published by the Nobel Foundation, "It may well be said that Lorentz was regarded by all theoretical physicists as the world's leading spirit, who completed what was left unfinished by his predecessors and prepared the ground for the fruitful reception of the new ideas based on the quantum theory. He received many honors and

distinctions, including a term as chairman of the International Committee on Intellectual Cooperation, the forerunner of UNESCO.

\section{J.J. Thomson (1856-1940)}

Joseph John Thomson Was an English physicist

and Nobel Laureate in Physics, credited with the discovery and identification of the electron; and with the discovery of the first subatomic particle. In 1897, Thomson showed that cathode rays were composed of previously unknown negatively charged particles, which he calculated must have bodies much smaller than atoms and a very large value for their charge-to-mass ratio

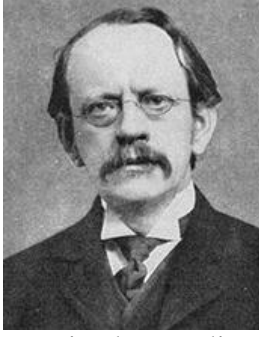

Thomson is also credited with finding the first evidence for isotopes of a stable (nonradioactive) element in 1913, as part of his exploration into the composition of canal rays (positive ions). His experiments to determine the nature of positively charged particles, with Francis William Aston, were the first use of mass spectrometry and led to the development of the mass spectrograph.

\section{Heinrich Rudolf Hertz (1857-1894)}

a German physicist who first conclusively proved the existence of the electromagnetic waves

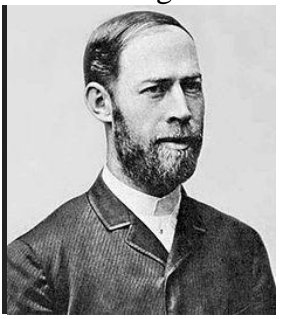

Hertz was theorized by James Clerk Maxwell's electromagnetic theory of light. He is the originator of the development of radio. The unit, of frequency-cycle per second - was named the "hertz" in his honor

\section{Max Planck}

(1858-1947)

Max Planck famous for the 'Planck's constant of action' was a German theoretical physicist whose discovery of energy quanta won him the Nobel Prize in Physics in 1918. Planck made many contributions to theoretical

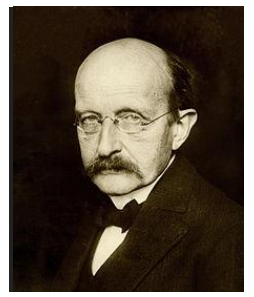




\section{International Advanced Research Journal in Science, Engineering and Technology}

Vol. 5, Issue 8, August 2018

physics, but his fame as a physicist rests primarily on his role as the originator of quantum theory, which revolutionized human understanding of atomic and subatomic processes. In 1948 the German scientific institution the Kaiser Wilhelm Society (of which Planck was twice president), was renamed the Max Planck Society (MPS). The MPS now includes 83 institutions representing a wide range of scientific directions.

\section{Pieter Zeeman} (1865-1943)

Pieter Zeeman was a Dutch physicist famous for the effect named after him known as the

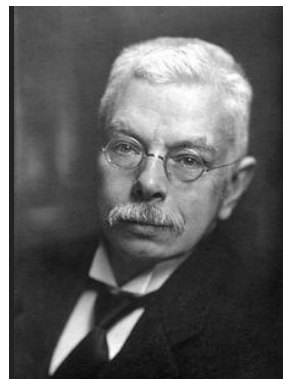

Zeeman Effect which is the effect of magnetic field on light with weak and strong magnetic fields. This discovery awarded him the Nobel Prize in 1902.

\section{Marie Curie} (1867-1934)

Marie Curie was a Polish and naturalized

French physicist and chemist who conducted pioneering research on radioactivity. She was the first woman to win a Nobel Prize, the first person and only woman to win twice, the only person to win a Nobel Prize in two different sciences, and was part of the Curie family legacy of five Nobel Prizes. She was also the first woman to

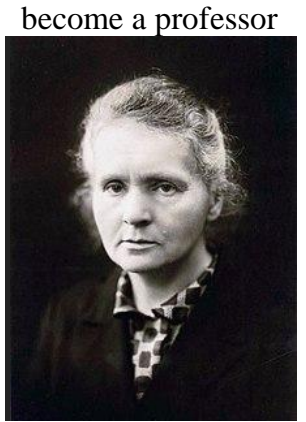

at the University of Paris, and in 1995 became the first woman to be entombed on her own merits in the Panthéon in Paris.

\section{Arnold Sommerfeld} (1868-1951)

Sommerfeld was a German theoretical physicist who pioneered developments in atomic and quantum physics, and also educated and mentored a large number of students for the new era of theoretical physics. He served as $\mathrm{PhD}$ supervisor for many Nobel Prize winners in physics and chemistry $\mathrm{He}$ introduced the 2nd quantum number (azimuthal quantum number) and the 4 th quantum

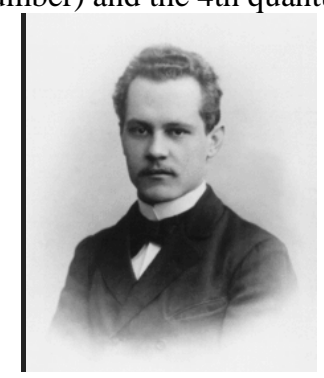

number (spin quantum number).

$\mathrm{He}$ also introduced the finestructure constant and pioneered Xray wave theory.

\section{Ernest Rutherford} (1871-1957)

Rutherford was a New Z ealandborn British physicist who came to be known as the father of nuclear physics Encyclopædia

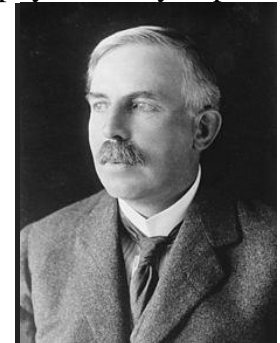

Britannica considers him to be the greatest experimentalist since Michael Faraday In his early work, Rutherford discovered the concept of radioactive half-life, the radioactive element, radon, and differentiated and named alpha and beta radiation.

This work was performed at McGill University in Canada. It is the basis for the Nobel Prize in Chemistry he was awarded in 1908 "for his investigations into the disintegration of the elements, and the chemistry of radioactive substances", for which he was the first Canadian and Oceanian Nobel laureate.

\section{Guglielmo Marconi} (1874-1937)

Marconi was an Italian inventor and electrical engineer known for his pioneering work on long-

distance radio transmission and for his development of Marconi's law and a radio telegraph system.

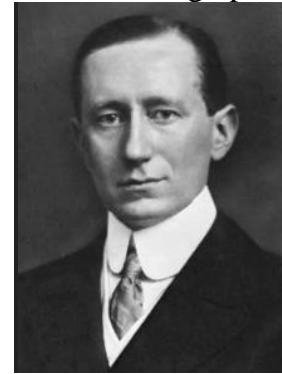

He is credited as the inventor of radio, and he shared the 1909 Nobel Prize in

Physics with Karl Ferdinand Braun "in recognition of their contributions to the development of wireless telegraphy". Marconi was also an entrepreneur, businessman, and founder of The Wireless

Telegraph \& Signal Company in the United Kingdom in 1897 (which became the Marconi Company). He succeeded in making an engineering and commercial success of radio by innovating and building on the work of previous experimenters and physicists. In 1929, Marconi was ennobled as

a Marchese (marquis) by King Victor Emmanuel III of

Italy and, in 1931, he set up the Vatican Radio for Pope Pius

XI.

\section{James Jeans} (1877-1946)

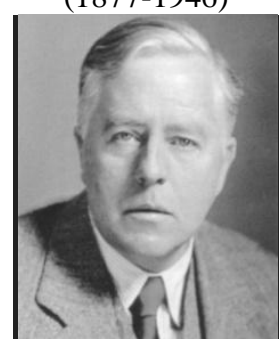

James Jeans was a British mathematical astrophysicist 


\section{International Advanced Research Journal in Science, Engineering and Technology}

Vol. 5, Issue 8, August 2018

graduated from Cambridge in 1900 and became fellow of Trinity

College. He was professor of

Applied Mathematics at Princeton, New Jersey, United States. Worked in the Mount

Wilson Observatory,

California, US. Developed Kinetic

Theory of Gases. He studied Black

Body Radiation along with Lord

Rayleigh and derived what is today known as Rayleigh-Jeans Formula.

\section{Albert Einstein} (1879-1955)

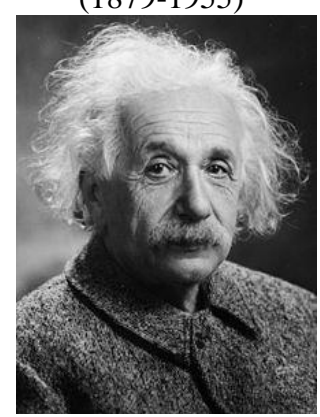

Einstein was a German-born theoretical physicist who developed the theory of relativity, one of the two pillars of modern physics (alongside quantum mechanics) His work is also known for its influence on the philosophy of science. the philosophy of science.He is best known to the general public for his massenergy equivalence formula, $E=m c^{2}$ which has been dubbed

"the world's most famous equation". He received the 1921 Nobel Prize in Physics "for his services to theoretical physics, and especially for his discovery of the law of the photoelectric effect", a pivotal step in the development of quantum theory. The transuranic element number 99 is named 'Einsteinium' in his honor.

\section{Arthur Stanley Eddington (1882-1944)}

Eddington was an English astronomer, physicist, and mathematician of the early 20th century who did his greatest work in astrophysics. He was also a philosopher of science and a populariser of science.

The Eddington limit, the natural limit to the luminosity of stars, or the radiation generated by accretion onto a compact object, is named in his honor. Around 1920, he anticipated the discovery and mechanism of nuclear

fusion processes in stars, in his paper "The Internal Constitution of the Stars". At that time, the source of stellar energy

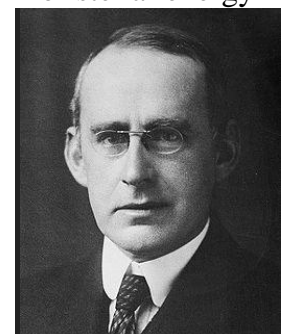

was a complete mystery Eddington was the first to correctly speculate that the source was fusion of hydrogen into helium. He is famous for his work concerning the theory of relativity. Eddington wrote a number of articles that announced and

explained Einstein's theory of general relativity to the Englishspeaking world.

\section{Max Born} (1882-1970)

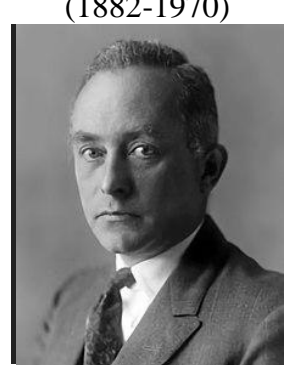

Max Born was a

German physicist and mathematici an who was instrumental in the development of quantum mechanics. He also made contributions to solid-state physics and optics and supervised the work of a number of notable physicists in the 1920s and 1930s. Born won the 1954 Nobel Prize in Physics for his "fundamental research in quantum mechanics, especially in the statistical interpretation of the wave function

\section{Peter Debye (1884-1966)}

Peter Joseph William Debye wellknown for his quantum theory of Specific Heats and the $\mathrm{T}^{3}$ law was a Dutch-
American physicist and physical cchemist, and, was a Nobel

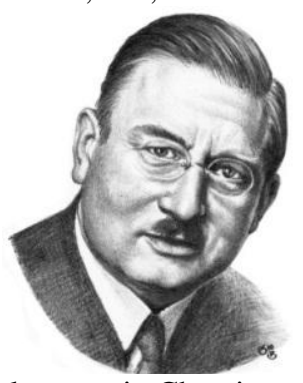

laureate in Chemistry

He published his first paper, a mathematically elegant solution of a problem involving eddy currents, in 1907. At Aachen, he studied under the theoretical physicist Arnold Sommerfeld, who later claimed that his most important discovery was Peter Debye.

He derived the Planck radiation formula using a method which Max Planck agreed was simpler than his own.

60. Niels Bohr (1885-1962)

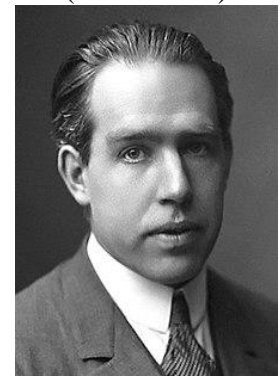

Bohr sometimes called the father of Atomic Physics was a

Danish physicist who made foundational contributions to understanding atomic

structure and quantum theory, for which he received the Nobel Prize in Physics in 1922. Bohr was also a philosopher and a promoter of scientific research.

Bohr developed the Bohr model of the atom, in which he proposed that energy levels of electrons are discrete and that the electrons revolve in stable orbits around the atomic nucleus but can jump from one energy level (or orbit) to another. Although the Bohr model

has been supplanted by other models, its underlying principles remain valid. He conceived the principle of complementarity: that items could be separately analyzed in terms of contradictory 


\section{International Advanced Research Journal in Science, Engineering and Technology}

Vol. 5, Issue 8, August 2018

properties, like behaving as a wave or a stream of particles. The notion

of complementarity dominated

Bohr's thinking in both science and philosophy

\section{Erwin Shrödinger}

(1887-1961)

Shrödinger was a Nobel Prize winning Austrian physicist who developed a number

of fundamental results in the field of quantum theory, which formed the basis of wave mechanics: he formulated the wave

equation (stationary and timedependent Schrödinger equation) and revealed the identity of his development of the formalism and matrix mechanics. Schrödinger proposed an original interpretation

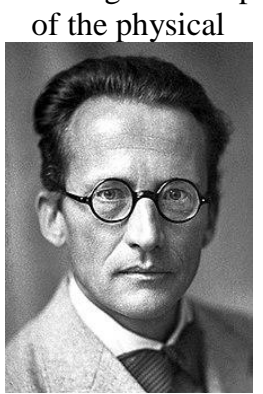

meaning of the wave function. In addition, he was the author of many works in various fields of physics: statistical mechanics and thermodynamics, physics of dielectrics, colour theory, electrodynamics, general relativity, and cosmology, and he made several attempts to construct a unified field theory.

\section{Sir C.V. Raman} (1888-1970)

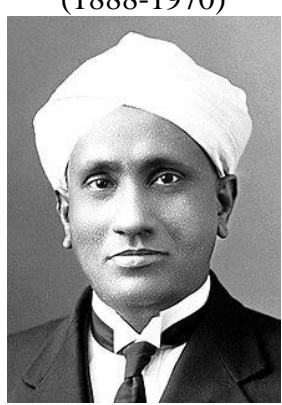

C.V. Raman was an Indian physicist born in the former Madras

Province in India presently the state of Tamil Nadu, who carried out ground-breaking work in the field of light scattering, which earned him the 1930 Nobel Prize for Physics. He discovered that when light traverses a transparent material . some of the deflected light changes wavelength. This phenomenon, subsequently known some of the deflected light changes wavelength.

as Raman scattering, or the Raman effect. In 1954, India honored him with its highest civilian award, the Bharat Ratna.

\section{James Chadwick} (1891-1974)

James Chadwick, sometimes called 'The father of Nuclear

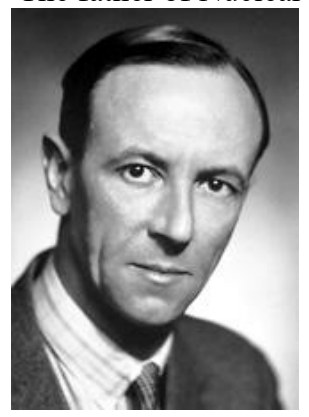

Physics and famous for the discovery of 'neutron' for which he was awarded the 1935 Nobel Prize,

was a member of the British scientific working group formed during the Second World War to work with the Manhattan project. to perform the research required to determine if an atomic bomb was feasible.

\section{Louis Victor de Broglie (1892-1987)}

De Broglie was a

French physicist who made ground-

breaking contributions to quantum theory. In his 1924 $\mathrm{PhD}$ thesis he postulated the wave nature of electrons and suggested that all matter has wave properties.

This concept is known as the de Broglie hypothesis, an example

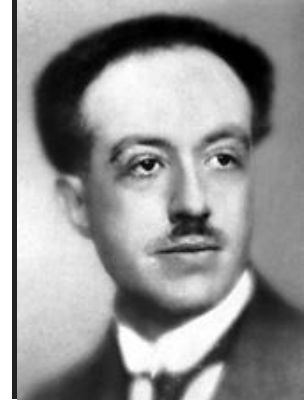

of wave-particle duality, and forms a central part of the theory of quantum mechanics.

De Broglie won the Nobel Prize for Physics in 1929, after the wavelike behaviour of matter was first experimentally demonstrated in 1927.

\section{Arthur Compton} (1892-1962)

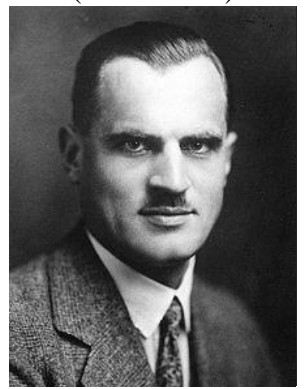

Compton, famous for the effect named after him, was an American physicist who won the Nobel Prize

in Physics in 1927 for his 1923

discovery of the Compton effect, which demonstrated the particle nature

of electromagnetic radiation. It was a sensational discovery at the time: the wave nature of light had been well-demonstrated, but the idea

that light had both wave and particle properties was not easily accepted. He is also known for his leadership of the Manhattan

Project's Metallurgical Laboratory, and served as Chancellor of Washington University in St. Louis from 1945 to 1953.

\section{Satyendra Nath Bose} (1894-1974)

Satyendra Nath Bose was an Indian physicist born in the present Bangala Desh specialised in theoretical physics. He is best known for his work on quantum 


\section{International Advanced Research Journal in Science, Engineering and Technology}

Vol. 5, Issue 8, August 2018

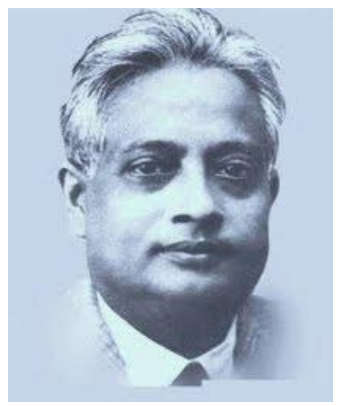

statistics in the early 1920 s, providing the foundation for BoseEinstein statistics and the theory of the Bose-Einstein condensate.

A Fellow of the Royal Society, he was awarded India's second highest civilian award,

the Padma Vibhushan in 1954 by the Government of India.

\section{Wolfgang Pauli} (1900-1958)

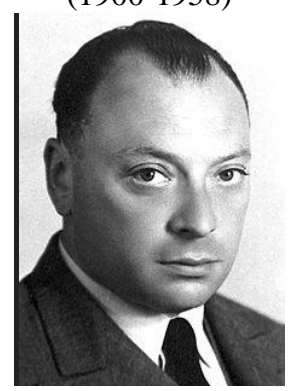

Pauli was an Austrianborn Swiss and American theoretical physicist and one of the pioneers of quantum physics. In 1945, after having been nominated by Albert Einstein Pauli received the Nobel Prize in Physics for his "decisive contribution through his discovery of a new law of Nature, the exclusion principle or Pauli principle". The discovery involved spin theory, which is the basis of a theory of the structure of matter.

\section{$20^{\text {th }}$ Century (1901-2000) 68. Enrico Fermi (1901-1954)}

Fermi was an Italy-born American physicist and the creator of the world's first nuclear reactor, the Chicago Pile-1. He related to the use of nuclear power, and was awarded the 1938 Nobel Prize in Physics for his work on induced radioactivity by neutron bombardment and the discovery of transuranic elements. He

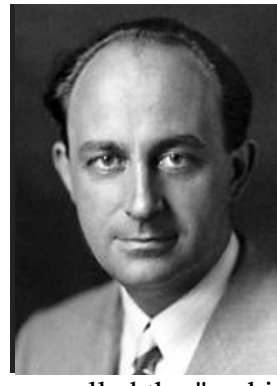

has been called the "architect of the nuclear age" and the "architect of the atomic bomb". He was one of the very few physicists in history to excel both theoretically and experimentally Fermi held several patents

interacted with Dirac in Quantum Statistics which came to be known as 'Fermi-Dirac Statistics. As a major part of the Manhattan project, an experimental reactor was built in the university of Chicago which went critical on 2 December 1942such as electrons

The US National Accelerator

Laboratory at Batavia, near

Chicago is named after him as the 'Fermi Lab'

\section{Werner Heisenberg} (1901-1976)

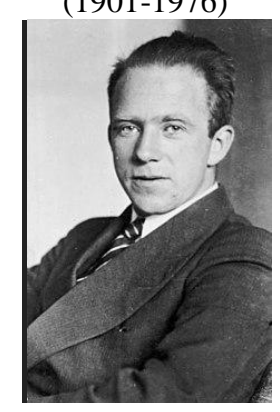

Heisenberg was

a German theoretical physicist and one of the key pioneers of quantum mechanics. He published his work in 1925 in a breakthrough paper. In the subsequent series of papers with Max Born and Pascual Jordan, during the same year, this matrix formulation of quantum mechanics was substantially elaborated. He is

known for the Heisenberg uncertainty principle, which he published in 1927 . Heisenberg was awarded the 1932 Nobel Prize in

Physics "for the creation of quantum mechanics" He also made important contributions to the theories of the hydrodynamics of turbulent flows, the atomic nucleus, ferromagnetism, co smic rays, and subatomic particles

\section{Earnest Lawrence} (1901-1958)

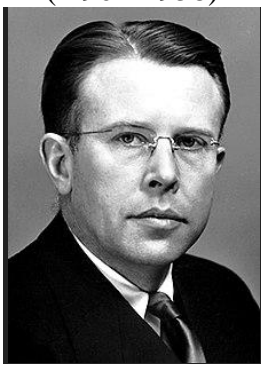

Earnest Lawrence was a pioneering American nuclear scientist and winner of the Nobel Prize in Physics in 1939 for his invention of the cyclotron. He is known for his work on uranium-isotope separation for the Manhattan Project, as well as for founding the National Laboratory at

Livermore, California. He made the first instrument known as the 'Cyclotron' for acceleration of charged particles.

After his death, the Regents of the University of

California renamed the Lawrence Livermore National

Laboratory and Lawrence Berkeley

National Laboratory after

him. Chemical element number 103 detected at his laboratory at the university of California at Berkeley is given the name, 'Lawrencium' in his honor. was

named lawrencium in his honor after its discovery at Berkeley in 1961.

\section{P.A.M. Dirac}

(1902-1984) Paul Andrien

Maurice Dirac was an

English theoretical physicist who is

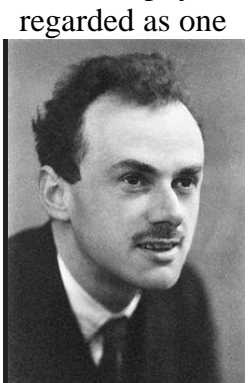

of the most significant physicists of the 20th century. Dirac made fundamental contributions to the early development of both quantum 


\section{International Advanced Research Journal in Science, Engineering and Technology}

Vol. 5, Issue 8, August 2018

mechanics and quantum electrodynamics

Among other discoveries, he formulated the Dirac equation which describes the behavior of fermions and predicted the existence of antimatter. Dirac shared the 1933 Nobel Prize in Physics with Erwin Schrödinger "for the discovery of new productive forms of atomic theory" He also made significant contributions to

the reconciliation of general relativity with quantum mechanics. $\mathrm{He}$ is regarded as the only theorist who is ranked with Isaac Newton in Pantheon Physics

\section{Robert}

\section{Oppenheimer} (1904-1967)

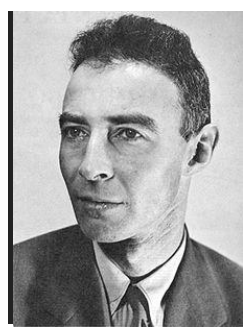

Julius Robert Oppenheimer was an American theoretical physicist and professor of physics at the University of California, Berkeley. Oppenheimer was the wartime head of the Los Alamos Laboratory and is among those who are credited with being the "father of the atomic bomb" for their role in the Manhattan Project, the World War II undertaking that developed the first nuclear weapons used in the atomic bombings of Hiroshima and Nagasaki. The first atomic bomb was detonated on July 16, 1945, in the Trinity test in New Mexico; Oppenheimer later remarked that it brought to mind words from the Bhagavad Gita: "Now I am become Death, the destroyer of worlds." After the war ended, Oppenheimer became chairman of the influential General Advisory

Committee of the newly created United States Atomic Energy Commission.

73. C.D. Anderson (1905-1991)

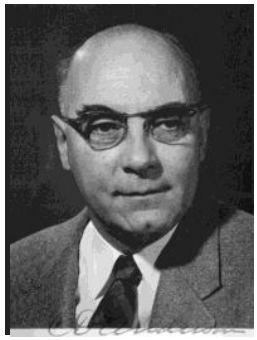

Carl David Anderson was an American physicist. He is best known for his discovery of the positron in 1932, an achievement for which he received the 1936 Nobel Prize in Physics, and of the muon in 1936.

Under the supervision of Robert A Millikan, he began investigations into cosmic rays during the course of which he encountered unexpected particle tracks in his (modern versions now commonly referred to as an Anderson) cloud chamber photographs that he correctly interpreted as having been created by a particle with the same mass as the electron, but with opposite electrical charge. This discovery, announced in 1932 and

later confirmed by others, validated Paul Dirac's

theoretical prediction of the existence of the positron

\section{Hideki Yukawa} (1907-1981)

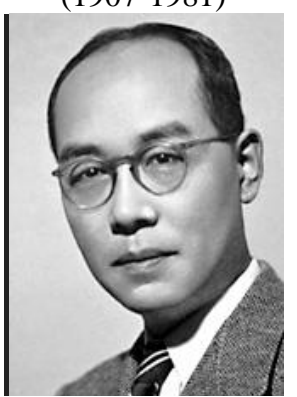

Yukawa was a Japanese theoretical physicist and the first Japanese Nobel Prize winner for his prediction of the Meson, a particle of mass mid-way between an electron and proton. It was initially named 'yukon' changed to 'mesotron' and shortened to 'meson'. 'mesos' means 'middle'. In 1935 he published his theory of mesons, which explained the interaction between protons and neutrons, and was a major influence on research into elementary particles. In 1940 he became a professor in Kyoto
University. In 1940 he won the Imperial Prize of the Japan Academy, in 1943 the Decoration of Cultural Merit from the Japanese government. In 1949 he became a professor at Columbia University, the same year he received the Nobel Prize in Physics

\section{John Bardeen} (1908-1991)

John Bardeen was an American physicist and electrical engineer.

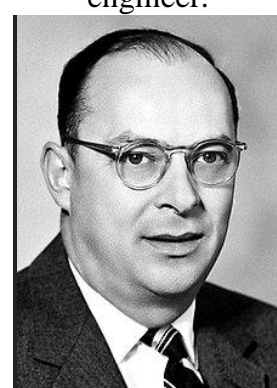

$\mathrm{He}$ is the only person who won the Nobel Prize in

Physics twice: first in 1956 with William Shockley and Walter

Brattain for the invention of the transistor; and again in 1972 with Leon N Cooper and John

Robert Schrieffer for a fundamental theory of conventional superconductivity kn own as the BCS theory.

The transistor revolutionized the electronics industry and ushered the birth of the Information Age.

The semiconductor device also made possible the development of almost every modern electronic device,

from telephones to computers to mi ssiles. Bardeen's developments in superconductivity - which won him his second Nobel Prize - are used in nuclear magnetic resonance spectroscopy (NMR) or its medical sub-tool magnetic resonance imaging (MRI).

In 1990, John Bardeen appeared on LIFE Magazine's list of "100 Most Influential Americans of the Century

\section{Subramanyan Chandrasekhar} (1910-1995) 


\section{International Advanced Research Journal in Science, Engineering and Technology}

Vol. 5, Issue 8, August 2018

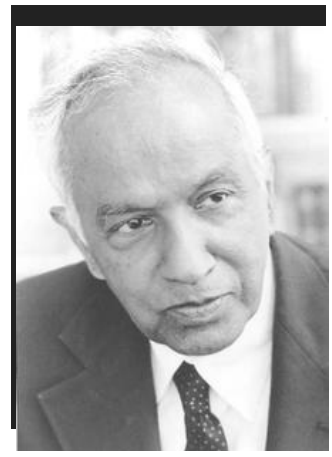

Subramanyan Chandrasekhar was an Indian American astrophysicist who spent his professional life in the United States. ${ }^{[4]} \mathrm{He}$ was awarded the 1983 Nobel Prize for Physics with William A.

Fowler for "...theoretical studies of the physical processes of importance to the structure and evolution of the stars". His mathematical treatment of stellar evolution yielded many of the best current theoretical models of the

later evolutionary stages of massive stars and black holes. ${ }^{[5][6]}$ The Chandrasekhar limit is named after him. He also worked on general relativity, mathematical theory of black holes and theory of colliding gravitational waves

\section{Nikolay Basov (1922-2001) Basov was} a Soviet physicist and educator. For his fundamental work in the field of quantum electronics that led to the development of laser and maser,

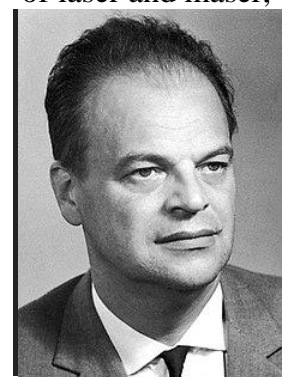

Basovsharedthe1964 Nobel Prize in Physics with Alexander Prokhorov and Charles Hard Townes

\section{Peter Higgs (b.1929- . )}

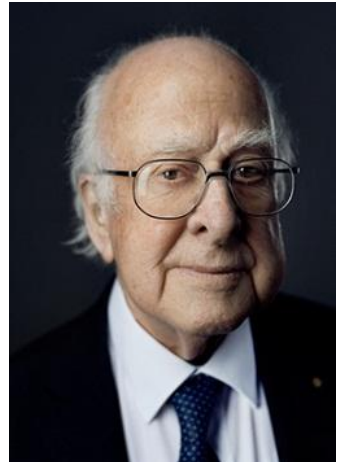

Peter Higgs is a British theoretical physicist, emeritus professor in the University of

Edinburgh, and Nobel

Prize laureate for his work on the mass of subatomic particles.

In the 1960s, he proposed that broken symmetry in electroweak theory could explain the origin of mass of elementary particles in general and of the $\mathrm{W}$ and $\mathrm{Z}$ bosons in particular. This socalled Higgs mechanism, which was proposed by several physicists besides Higgs at about the same time, predicts the existence of a new particle, the Higgs boson, the detection of which became one of the great goals of physics. CERN announced on 4 July 2012 that they had experimentally established the existence of a Higgs-like boson which brought the 2013 Nobel Prize.

\section{Murray Gell-Man} (b.1929...)

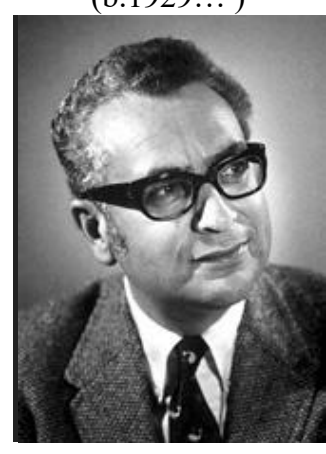

The quark model was independently proposed by physicists Murray Gell-Mann and George Zweig in

1964.Quarks were introduced as parts of an ordering scheme for hadrons, and there was little evidence for their physical existence until deep inelastic scattering experiments at the
Stanford Linear Accelerator Center in 1968. Murray Gell-Man is an American physicist who received the 1969 Nobel Prize in physics for his work on the theory

of elementary particles. He is the Robert Andrews

Millikan Professor of Theoretical Physics Emeritus at the California Institute of Technology, a distinguished fellow and co-

founder of the Santa Fe Institute, a professor of physics at the University of New Mexico, and the Presidential Professor of Physics and Medicine at the University of Southern California.

\section{Kip Stephen Thorne} (b. $1940 \ldots$ )

Kip Stephen Thorne is an American theoretical physicist working on Gravitational-wave astronomy is an emerging branch of observational astronomy which aims to use gravitational waves (minute Distortions of space time predicted by Einstein's theory of general relativity) to collect observational data about objects such as neutron stars and black holes, events such as supernovae, and processes including those of the early universe shortly after

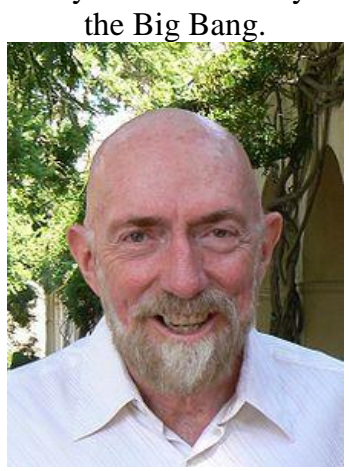

Gravitational waves have a solid theoretical basis, founded upon the theory of relativity. They were first predicted by Einstein in 1916; although a specific consequence of general relativity, they are a common feature of all theories of gravity that obey special relativity. ${ }^{[3]}$. However, after 1916 there was a long debate whether the waves were actually physical, or artifacts of coordinate freedom in general relativity; this was not fully resolved until the 1950s. Indirect observational evidence for their existence first came in the late 


\section{International Advanced Research Journal in Science, Engineering and Technology}

Vol. 5, Issue 8, August 2018

1980s, from monitoring of the Hulse-Taylor binary pulsar (discovered 1974); the pulsar orbit was found to evolve exactly as would be expected for gravitational wave

emission. ${ }^{[4]}$ Hulse and Taylor were awarded the 1993 Nobel Prize in Physics for this

discovery. On 11 February 2016 it was announced that

the LIGO collaboration

had directly observed gravitational waves for the first time in September 2015. Barry Barish, Kip Thorne and Rainer Weiss were awarded the 2017 Nobel Prize in Physics for leading this work.

\section{Stephen Hawking}

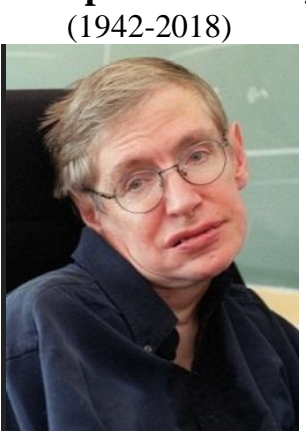

Hawking was an nglish theoretical physicist, cosmologist, and author, who was director of research at the center for Theoretical Cosmology at the University of Cambridge. at the time of his is death. He was the Lucasian Professor of Mathematics at the University of
Cambridge between 1979 and

2009. Hawking achieved

commercial success with several

works of popular science in which

his book A Brief History of

Time appeared on the

British Sunday Times best-seller

list for a record-breaking 237

weeks. Hawking was a fellow of the Royal Society (FRS), a lifetime member of the Pontifical Academy of Sciences

\section{Carl Wieman}

(b.1951...)

Carl Wieman is an

American physicist and educationis $\mathrm{t}$ at Stanford University. In 1995, while at the University of Colorado Boulder, he and Eric Allin Cornell produced the first

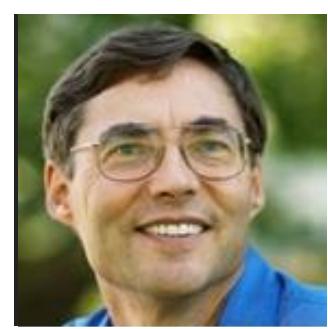

Carl Wieman is an true BoseEinstein condensate(BEC) and, in Ketterle (for further BEC studies) were awarded the Nobel Prize in Physics. 2001, they and Wolfgang

\section{Wolfgang Ketterie}

(b.1957...)

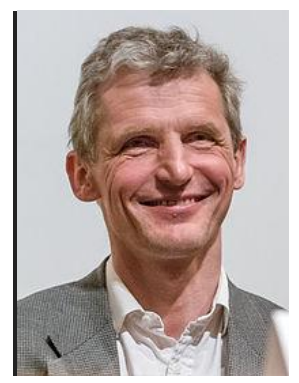

Wolfgang Ketterie is a German physicist and professor of physics at the Massachusetts Institute of Technology (MIT). His research has focused on experiments that

trapand cool atoms to temperatures close to absolute zero, and he led one of the first groups to realize Bose-Einstein condensation in these systems in 1995. For this achievement, as well as early fundamental studies of condensates, he was awarded the Nobel Prize in Physics in 2001, together with Eric Allin

Cornell and Carl Wieman.

The number is really large running into some 83 in spite of deliberately excluding few to decrease the number

It is seen from the above that, in spite of choosing maximum number of scientists from each century, there are very few scientists in the earlier periods up to the $16^{\text {th }}$ century. That is, up to the end of the $15^{\text {th }}$ century, there are only 9 scientists. We are just making a tentative assessment of the advancement research in Physics as on today. We shall make a tabular form as shown in Table No.1

Table No.1

\begin{tabular}{|c|c|c|c|}
\hline No. & Period & Year & No. of Scientists \\
\hline 1 & Classical Greece & $480 \mathrm{BC}-399 \mathrm{BC}$ & 2 \\
\hline 2 & Macedonian Era & $399 \mathrm{BC}-323 \mathrm{BC}$ & 1 \\
\hline 3 & Hellenistic Greece & $323 \mathrm{BC}-146 \mathrm{BC}$ & 2 \\
\hline 4 & Late Roman Republic & $147 \mathrm{BC}-27 \mathrm{BC}$ & 1 \\
\hline 5 & $\begin{array}{c}\text { Principate of the Roman } \\
\text { Empire }\end{array}$ & $27 \mathrm{BC}-284 \mathrm{AD}$ & 1 \\
\hline 6 & Late Antiquity & $284 \mathrm{AD}-500 \mathrm{AD}$ & Nil \\
\hline 7 & $10^{\text {th }}$ Century & $901-1000$ & 1 \\
\hline
\end{tabular}




\section{International Advanced Research Journal in Science, Engineering and Technology}

Vol. 5, Issue 8, August 2018

\begin{tabular}{|c|l|l|c|}
\hline 8 & $15^{\text {th }}$ Century & $1401-1500$ & 1 \\
\hline 9 & $16^{\text {th }}$ Century & $1501-1600$ & 4 \\
\hline 10 & $17^{\text {th }}$ Century & $1601-1700$ & 4 \\
\hline 11 & $18^{\text {th }}$ Century & $1701-1800$ & 14 \\
\hline 12 & 19 Century & $1801-1900$ & 36 \\
\hline 13 & $20^{\text {th }}$ Century & $1901-2000$ & 16 \\
\hline
\end{tabular}

Total No. of Scientists considered: 83

From the Table No.1 it is seen that prior to $16^{\text {th }}$ century and up to end of $15^{\text {th }}$ century, there are only 9 scientists over a period of over 1000 years. This is probably because the number of people interested in Science was much less due to the fact that people knowing something were few and people knowing nothing were many and hence let us reduce the table and make a new one and the same is shown in Table No. 2

Table No.2

\begin{tabular}{|c|c|}
\hline Period & No. of Scientists \\
\hline Up to end of $15^{\text {th }}$ Century & 9 \\
\hline $16^{\text {th }}$ Century & 4 \\
\hline $17^{\text {th }}$ Century & 4 \\
\hline $18^{\text {th }}$ Century & 14 \\
\hline $19^{\text {th }}$ Century & 36 \\
\hline $20^{\text {th }}$ Century & 16 \\
\hline
\end{tabular}

Total No. of Scientists: 83

Now, plot a bar graph of Number of Scientists versus Centuries and the nature of graph is shown in Fig.3. Up to $15^{\text {th }}$ century, there is a reasonable increase shown by the black bar and is not satisfactory as the same is obtained over many centuries. From $15^{\text {th }}$ to $16^{\text {th }}$ century, there is a decrease and the same is maintained up to $17^{\text {th }}$ century shown by the green bar. From $17^{\text {th }}$ century to $19^{\text {th }}$ century there is a renaissance of development shown by the blue bar of some 36 scientists. Later the number came down to just 16 in the $20^{\text {th }}$ century shown by the violet bar.

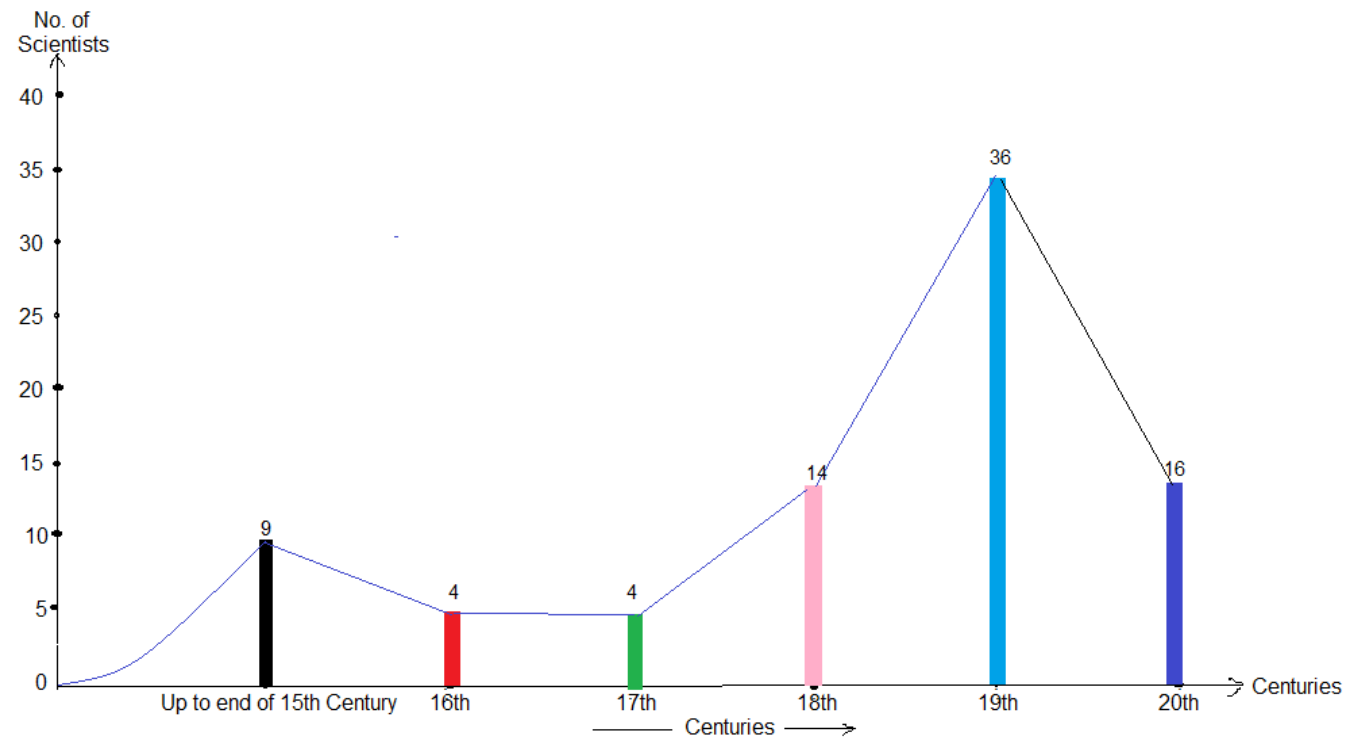

Fig.3 The Mode of growth of development of research in Physics

Looking upon an overall view of the situation after going through the work done by the scientists, it is seen that when Mathematics which is the language of Physics was just Arithmetic of counting numbers (Fig 4) [10], the development over centuries was tremendous from Algebra of Al-Khwarizmi to Calculus of Newton, various 
Differential equations of Laplace, the complicated equation, $R_{\mu v}-\frac{1}{2} R g_{\mu v}=\frac{8 \pi G}{c^{4}} T_{\mu v}$ of General Theory obtained by Einstein using Tensors or the Klein-Gordon Equation, D’Alembertian,

$\frac{1}{\mathrm{c}^{2}} \frac{\mathrm{d}^{2} \psi}{\mathrm{dt}^{2}}-\frac{\mathrm{d}^{2} \psi}{\mathrm{dx}^{2}}-\frac{\mathrm{d}^{2} \psi}{\mathrm{dy}^{2}}-\frac{\mathrm{d}^{2} \psi}{\mathrm{dz}^{2}}=-\mathrm{K} \psi=\square \psi$ used by Peter Higgs in the explanation of creating mass in the elementary particles.

3.2 Publications: From a historical point of view, some of the ancient and important publications in Physics to date are enlisted in Table No.3

Table No.3

\begin{tabular}{|c|c|c|c|c|}
\hline No. & Author & Period & Title of Publication & Year \\
\hline 1 & Aristotle & $384-322$ BC & Physical Auscultations & \\
\hline 2 & Archimedes & $287-212$ BC & on Floating Bodies & \\
\hline 3 & Ptolemy & $100-170$ AD & Almgest Geographica Apotelesmatika & 1543 \\
\hline 4 & Alhazen & $965-1040$ AD & Book of Optics & 1632 \\
\hline 5 & Copernicus & $1473-1543$ & On the Revolutions of Celestial Spheres & 1641 \\
\hline 6 & Galileo & $1564-1642$ & Dialogue concerning the Two Chief World Systems & 1687 \\
\hline 7 & Descartes & $1596-1650$ & Meditations on First Philosophy & $1839 / 1844$ \\
\hline 8 & Newton & $1642-1727$ & Philosophiae Mathematica & 1873 \\
\hline 9 & Faraday & $1791-1727$ & Experimental Electricity (Project of Gutinberg) \\
\hline 10 & Maxwell & $1831-1879$ & A Treatise on Electricity and Magnetism & 1905 \\
\hline 11 & Einstein & $1879-1955$ & Annus Mirabilis Papers & \\
\hline
\end{tabular}
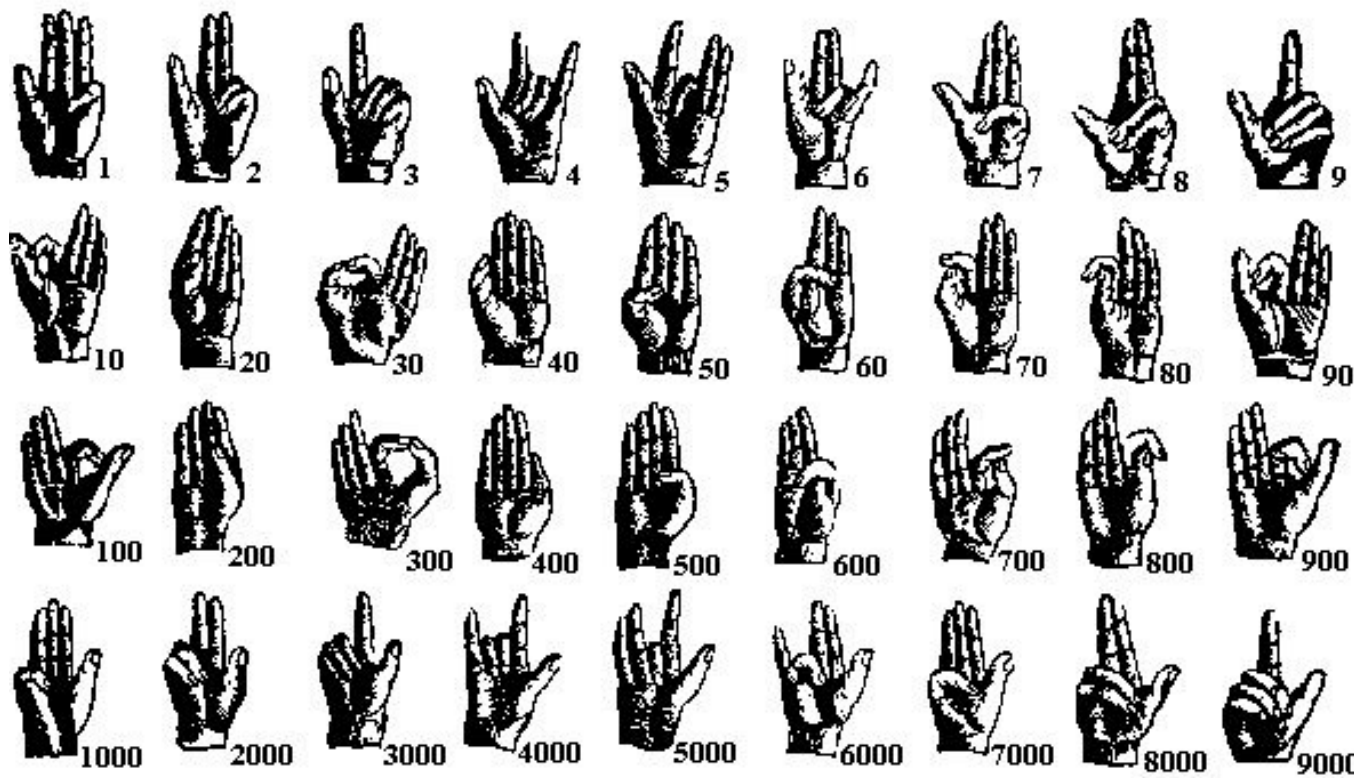

FINGER SYMBOLS

(From a manual published in 1520)

Fig.4 Finger symbols indicating numbers [10]

Our attention, now, will be on Peter Ware Higgs and his works stretching from 1964 to 2012. We start with the Standard Model of Particle Physics. 


\section{International Advanced Research Journal in Science, Engineering and Technology}

Vol. 5, Issue 8, August 2018

4.1The standard model: The Standard Model is an elegant theoretical model, the name given in the 1970s to a theory of fundamental particles and how they interact. It incorporated all that was known about subatomic particles at the time and predicted the existence of additional particles as well.

There are seventeen named particles in the standard model, organized into the chart shown in Table No.4 and the same is self-explanatory The last particles discovered were the $\mathrm{W}$ and $\mathrm{Z}$ bosons in 1983, the top quark in 1977, the tau neutrino in 2000, and the Higgs boson in 2012.

All the 16 particles out of the 17 were discovered except the Higgs Boson which is the critical ingredient for the understanding of the Standard Model, remained elusive.It was hypothesized in 1964, when British physicist Peter Higgs and several colleagues (François Englert, Robert Brout, Tom Kibble, Carl R. Hagen and Gerald Guralnik) showed by purely mathematical derivations that if there exists a

Table No.4

Particles of Standard Model with nucleons included for comparison [5]

\begin{tabular}{|c|c|c|c|c|c|c|c|c|c|}
\hline \multicolumn{3}{|c|}{ Family } & \multirow{2}{*}{$\begin{array}{l}\text { Particle } \\
\text { (1)up Quark }\end{array}$} & \multirow{2}{*}{$\begin{array}{l}\begin{array}{l}\text { Predic } \\
\text {-ted }\end{array} \\
1964\end{array}$} & \multirow{2}{*}{$\begin{array}{l}\begin{array}{l}\text { Discov- } \\
\text { ered }\end{array} \\
1968\end{array}$} & \multirow{2}{*}{$\begin{array}{c}\text { Spin } \\
\text { No. } \\
\frac{1}{2}\end{array}$} & \multirow{2}{*}{$\begin{array}{c}\text { Charge } \\
\text { e }\end{array}$} & \multirow{2}{*}{$\begin{array}{l}\text { Color } \\
\text { R G B }\end{array}$} & \multirow{2}{*}{$\begin{array}{c}\begin{array}{c}\text { Mass* } \\
\text { MeV }\end{array} \\
\mathbf{c}^{\mathbf{2}}\end{array}$} \\
\hline & $\mathrm{Q}$ & $\mathbf{u}$ & & & & & & & \\
\hline & $\bar{U}$ & d & $\begin{array}{l}\text { (2)down } \\
\text { Quark }\end{array}$ & 1964 & 1968 & $\frac{1}{2}$ & $-\frac{1}{3}$ & R G B & 4.7 \\
\hline $\mathrm{F}$ & $\overline{\mathrm{A}}$ & c & $\begin{array}{l}\text { (3) charm } \\
\text { Quark }\end{array}$ & 1970 & 1974 & $\frac{1}{2}$ & $+\frac{2}{3}$ & R G B & 1280 \\
\hline $\mathrm{E}$ & $\mathrm{R}$ & $\mathbf{s}$ & $\begin{array}{l}\text { (4) strange } \\
\text { Quark }\end{array}$ & 1964 & 1968 & $\frac{1}{2}$ & $-\frac{1}{3}$ & R G B & 96 \\
\hline $\mathrm{R}$ & $\mathrm{K}$ & $\mathbf{t}$ & $\begin{array}{l}\text { (5) top } \\
\text { Quark }\end{array}$ & 1973 & 1977 & $\frac{1}{2}$ & $+\frac{2}{3}$ & R G B & 173100 \\
\hline $\mathrm{M}$ & $S$ & b & $\begin{array}{l}\text { (6) bottom } \\
\text { Quark }\end{array}$ & 1973 & 1977 & $\frac{1}{2}$ & $-\frac{1}{3}$ & R G B & 4180 \\
\hline I & $\mathrm{L}$ & $\mathbf{e}$ & (7) )electron & 1874 & 1897 & $\frac{1}{2}$ & -1 & Nil & 0.511 \\
\hline $\mathrm{O}$ & $\mathrm{E}$ & $\mu$ & (8) $\mu \mathrm{on}$ & & 1936 & $\frac{1}{2}$ & -1 & Nil & 105.6584 \\
\hline $\mathrm{N}$ & $\mathrm{P}$ & $\mathbf{T}$ & (9) Tau & & 1975 & $\frac{2}{2}$ & -1 & Nil & $1,7760.86$ \\
\hline \multirow[t]{5}{*}{$\mathrm{S}$} & $\mathrm{T}$ & $\mathbf{V}_{\mathrm{e}}$ & $\begin{array}{l}\text { (10) Electron } \\
\text { neutrino }\end{array}$ & 1930 & 1956 & $\frac{1}{2}$ & 0 & Nil & $<10^{-7}$ \\
\hline & $\mathrm{O}$ & $\mathbf{V}_{\mu}$ & $\begin{array}{l}\text { (11) } \mu \text { on } \\
\text { neutrino }\end{array}$ & 1940's & 1962 & $\frac{1}{2}$ & 0 & Nil & $<10^{-7}$ \\
\hline & $\mathrm{N}$ & $\overline{V_{T}}$ & $\begin{array}{l}\text { (12)Tau } \\
\text { neutrino }\end{array}$ & 1970's & 2000 & $\frac{1}{2}$ & 0 & Nil & $<10^{-7}$ \\
\hline & & $\mathbf{p}$ & proton & 1815 & 1917 & $\frac{1}{2}$ & +1 & Nil & 938.27 \\
\hline & & n & neutron & 1920 & 1932 & $\frac{1}{2}$ & 0 & Nil & 939.6 \\
\hline B & $\mathrm{V}$ & g & (13)gluon & 1962 & 1978 & 1 & 0 & 8 colors & 0 \\
\hline $\mathrm{O}$ & $\mathrm{E}$ & $v$ & $\begin{array}{l}\text { (14) } \\
\text { Photon }\end{array}$ & & 1899 & 1 & 0 & Nil & 0 \\
\hline$S$ & $\mathrm{C}$ & $\mathbf{W}$ & $\begin{array}{l}\text { (15) } \\
\text { W boson }\end{array}$ & 1968 & 1983 & 1 & \pm 1 & Nil & 80,385 \\
\hline $\mathrm{O}$ & $\mathrm{T}$ & $\mathbf{Z}$ & $\begin{array}{l}\text { (16) } \\
Z \text { boson }\end{array}$ & 1968 & 1983 & 1 & 0 & Nil & 91,1876 \\
\hline $\mathrm{N}$ & OR & $\mathbf{H}$ & $\begin{array}{l}\text { (17)Higgs } \\
\text { boson }\end{array}$ & 1964 & 2012 & 0 & 0 & Nil & 125,090 \\
\hline
\end{tabular}

There are 17 particles with number put in brackets of the Particles column in the above Table

Note: 1. *Masses obtained from "Particle Data Group" 


\title{
International Advanced Research Journal in Science, Engineering and Technology
}

\author{
Vol. 5, Issue 8, August 2018
}

2. Serial Nos.(13), (14), (15) and (16) are called Gauge bosons. Serial No. 17 Higgs boson is the only scalar boson.

$\mathrm{R} \rightarrow$ Red, $\mathrm{G} \rightarrow$ Green and B $\rightarrow$ Blue

universal background field of a certain type, then particles that convey forces would behave as if they have mass. Subsequently, Texas physicist Steven Weinberg (who shared the 1979 Nobel prize with Abdus Salam and Sheldon Glashow) showed that this same idea could be applied to all fundamental particles, including protons, neutrons and electrons.

4.2 The Higgs Bang: I call it "The Higgs Bang" rather than the "Big Bang" because it is Peter Higgs who predicted this particle in 1964. We need some Mathematics. The Math Pages [7] has given elaborately and the same I have abridged.

According to the Big Bang theory, what existed at the beginning of the universe is the Higgs Boson which created other particles, that is, it gave mass to millions, billions or trillions of massless particles called bosons. How they gave or by what mechanism the masses were given is a big question and many theorists argue differently on this. What is required is some Mathematics which of course is going to be rigorous. Let us consider a continuous scalar field in space- time, $\psi(\mathrm{x}, \mathrm{y}, \mathrm{z}, \mathrm{t})$ in the form:

$$
\frac{1}{\mathrm{c}^{2}} \frac{\mathrm{d}^{2} \psi}{\mathrm{dt}^{2}}-\frac{\mathrm{d}^{2} \psi}{\mathrm{dx}^{2}}-\frac{\mathrm{d}^{2} \psi}{\mathrm{dy}^{2}}-\frac{\mathrm{d}^{2} \psi}{\mathrm{dz}^{2}}=-K \psi=\square \psi \ldots \ldots \ldots \ldots \ldots \text { (1) }
$$

where $\mathrm{c}$ is the speed of light and $\mathrm{K}$ a constant. The quantity on the left is the D'Alembertian and the equation is known as the Klein,-Gordon equation. The equation has two distinct cases to consider. If the constant $\mathrm{K}$ is zero, then energy $\mathrm{E}$ and scaled momentum of any excitation of the field are equal and such an excitation corresponds to a massless particle propagating at the speed of light. On the other hand, if $\mathrm{K}$ has a non-zero (+ ve) value, any excitation of the field has energy that exceeds its scaled momentum given by the standard relativistic energy-momentum equation, $E^{2}-c^{2} p^{2}=$ $\mathrm{c}^{4} \mathrm{~m}^{2}$ and corresponds to a matter wave whose phase velocity $\mathrm{V}$ exceeds the speed of light and whose group velocity, $\mathrm{v}$ is less than the speed of light such that $\mathrm{vV}=\mathrm{c}^{2}$. We may surmise that since a massive particle has energy that exceeds its scaled momentum, it must possess one or more intrinsic modes of energy.

For an interaction, let us consider two fields, $\psi_{1}$ and $\psi_{2}$ so that the governing equations become

$$
\begin{aligned}
& \square \psi_{1}=-\left(\mathrm{K}_{1}+\mathrm{k}_{12} \psi_{2}^{2}\right) \psi_{1} \text { and } \\
& \square \Psi_{2}=-\left(\mathrm{K}_{2}+\mathrm{k}_{21} \psi_{1}^{2}\right) \psi_{2} \ldots \ldots . . . . .
\end{aligned}
$$

where the symbols $\mathrm{k}_{12}$ and $\mathrm{k}_{21}$ are equal positive constants representing the coupling strength between the two fields. If $\mathrm{k}_{12}$ is 0 , then the fields $\psi_{1}$ and $\psi_{2}$ do not interact.

In general, if there are ' $n$ ' fields, $\psi_{1}, \psi_{2}, \psi_{3} \ldots \ldots \psi_{n}$, for each pair $\psi_{i}$ and $\psi_{\mathrm{j}}$ we have specific coupling constant, $\mathrm{k}_{\mathrm{ij}}\left(=\mathrm{k}_{\mathrm{ji}}\right)$. To account for the possibility of interaction, equation (1) is modified to include the interaction contributions and written as:

$$
\square \psi_{i}=-\left(K_{\mathrm{i}}+\sum_{\mathrm{j}=1}^{\mathrm{n}} \mathrm{k}_{\mathrm{ij}} \psi_{\mathrm{j}}^{2}\right) \psi_{\mathrm{i}} \ldots \ldots \ldots \ldots \ldots
$$

The simplest case is for the isolated field, $\Psi_{i}$ with $\mathrm{K}_{\mathrm{i}}=0$ so that we are left with $\square \psi_{i}=0$ which has a steady state solution, $\psi_{i}=0$. Any disturbances propagating in such field will be small and their squares will be still smaller and hence the summation on the right of equation (3) will be extremely small even in the presence of other fields. Hence all the particles would be essentially massless moving with speed of light.

Now, let us suppose that there exists a field $\psi_{i}$ with non-zero $\mathrm{K}_{\mathrm{i}}$ and with a non -zero interaction coefficient $\mathrm{k}_{\mathrm{ii}}$. Such a field in isolation satisfies the equation,

$$
\square \psi_{i}=-\left(\mathrm{K}_{\mathrm{i}}+\mathrm{k}_{\mathrm{ii}} \psi_{\mathrm{i}}^{2}\right) \psi_{\mathrm{i}}
$$

At steady state, the left side of equation (4) vanishes and this equation is satisfied if either of the factors on the right side vanish. One solution is, $\psi_{i}=0$, but there are also two other solutions given by the two roots of the quadratic factor in parenthesis, namely,

$$
\psi_{i}= \pm \sqrt{-\frac{\mathrm{K}_{\mathrm{i}}}{\mathrm{k}_{\mathrm{ii}}}} \ldots \ldots \ldots \ldots \ldots
$$




\section{International Advanced Research Journal in Science, Engineering and Technology}

Vol. 5, Issue 8, August 2018

In order to find which of the solutions is applicable, we have to find how the potential energy $\varphi$ of the field depends on the strength of the field. If we identify the right side of the equation (4) with the negative partial derivative, $-\left(\frac{\partial \phi}{\partial \psi_{i}}\right)$, then the potential has the quartic form,

$$
\phi=\frac{1}{2} \mathrm{~K}_{\mathrm{i}} \psi_{\mathrm{i}}^{2}+\frac{1}{4} \mathrm{k}_{\mathrm{ii}} \psi_{\mathrm{i}}^{4} \ldots \ldots \ldots \ldots \ldots
$$

As $\psi_{\mathrm{i}}$ is complex, we must envisage a 3-dimensional figure resembling a "Mexican Hat" with the energy trough surrounding a central hill and hence the zero solution is unstable.

Given the existence of one field, $\psi_{i}$ with negative $\mathrm{K}_{\mathrm{i}}$ and positive $\mathrm{k}_{\mathrm{ii}}$, the governing equation (4) for any other field, $\psi_{\mathrm{j}}$ with non-zero $\mathrm{k}_{\mathrm{ii}}$ will have an appreciable contribution to its effective mass due to the coupling with the $\psi_{i}$ field. In the absence of excitations in any other field, the governing equations for the $\psi_{\mathrm{j}}$ is:

$$
\square \psi_{\mathrm{j}}=-\left[\mathrm{K}_{\mathrm{j}}-\mathrm{k}_{\mathrm{ij}}\left(\frac{\mathrm{K}_{\mathrm{i}}}{\mathrm{k}_{\mathrm{ii}}}\right)\right] \psi_{\mathrm{j}}
$$

This shows that excitations of a field, $\psi_{j}$ with $K_{j}=0$ could nevertheless exhibit an effective rest mass due entirely to their interaction with the special field whose steady state value is non-zero as described above. That is, the wave equation for ordinary fields could be:

$$
\square \psi_{\mathrm{j}}=\mathrm{k}_{\mathrm{ij}}\left(\frac{\mathrm{K}_{\mathrm{i}}}{\mathrm{k}_{\mathrm{ii}}}\right) \psi_{\mathrm{j}}
$$

Where $\mathrm{K}_{\mathrm{i}}$ is negative. Comparing this with equation (1), we see that excitations of the field $\Psi_{\mathrm{j}}$ propagates like particles with an effective rest mass of:

$$
\left.\mathrm{m}_{\mathrm{j}}=\frac{\hbar}{\mathrm{c}} \sqrt{\left[\mathrm{k}_{\mathrm{ij}}\right.}\left(-\frac{\mathrm{K}_{\mathrm{i}}}{\mathrm{k}_{\mathrm{ii}}}\right)\right] \ldots \ldots \ldots \ldots
$$

With a suitable negative value of $\psi_{i}$ and positive $\mathrm{k}_{\mathrm{ii}}$, this function has three extrema as shown in Fig. 5

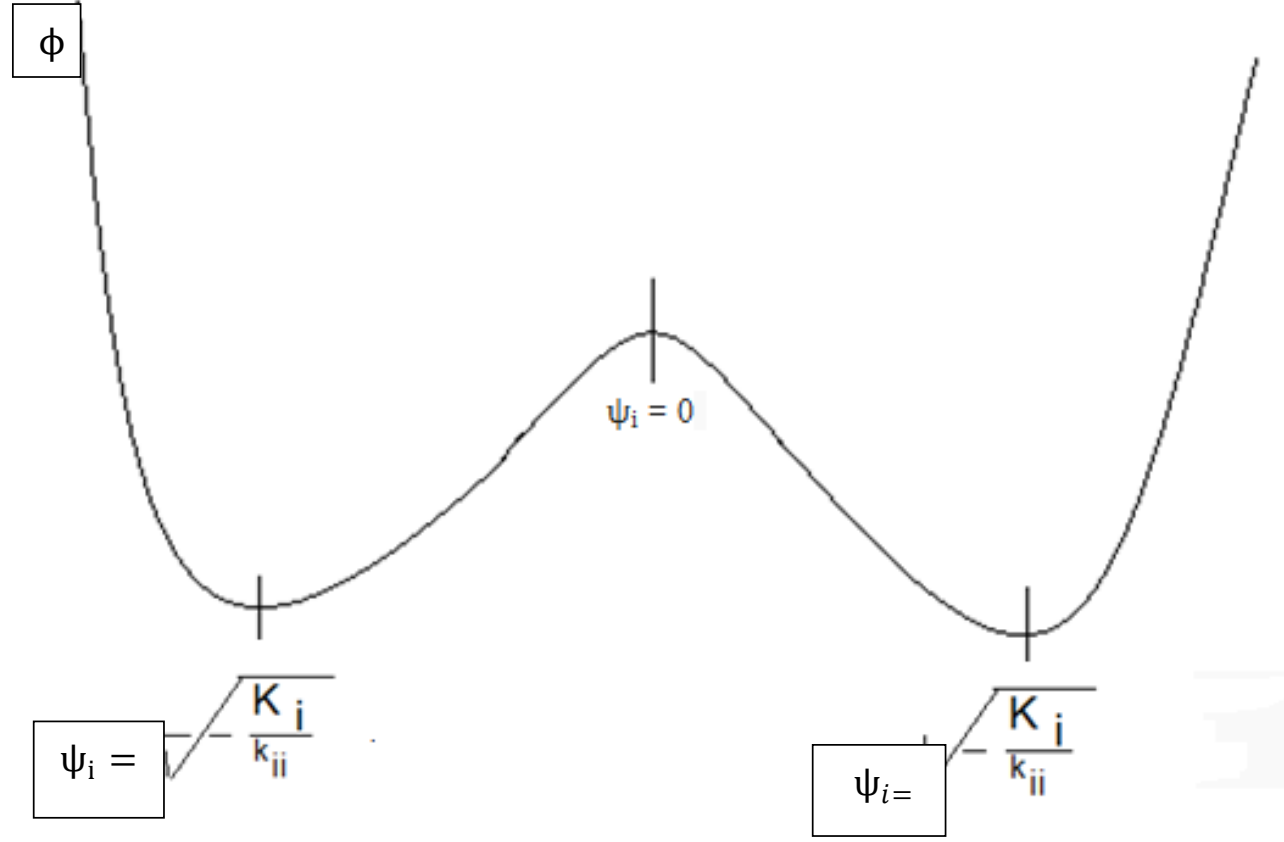

Fig.5 Graph of the 'Mexican Hat Potential'

due to the interaction between the $\psi_{\mathrm{j}}$ field and the special $\psi_{\mathrm{i}}$ field.

According to Standard Model of Particle Physics, most of the fundamental particles in nature having rest masses such as leptons and quarks are all excitations of fields whose governing equations have $\mathrm{K}_{\mathrm{j}}=0$ and $\mathrm{k}_{\mathrm{ii}}=0$. So, the particles would be mass less by themselves. The particles have an effective mass only because of the existence of a special field, called Higgs Field, whose governing equation has a negative $\mathrm{K}_{\mathrm{i}}$ and positive $\mathrm{k}_{\mathrm{ii}}$. The Higgs Field with a non-zero value in the steady state and the excitations of any field $\psi_{\mathrm{j}}$ that couples with the Higgs Field will propagate like a particle with effective rest mass given by equation (9).

The Higgs Field is Lorentz-invariant and simply facilitates the coupling between different modes of particle. 


\title{
International Advanced Research Journal in Science, Engineering and Technology
}

\author{
Vol. 5, Issue 8, August 2018
}

The rest mass arises from a "Broken Symmetry" of the Mexican Hat Potential. In the extremely hot conditions such as are thought to have existed in the first fraction of a second after the "Big Bang", the symmetry would not have broken, and all particles would be essentially mass less.

Brian Randolph Greene (b.1963...) [3] has avoided such a lethargic treatment as given above. He has been very brief in a U-Tube presentation which is analytical and the same is interesting and given here.

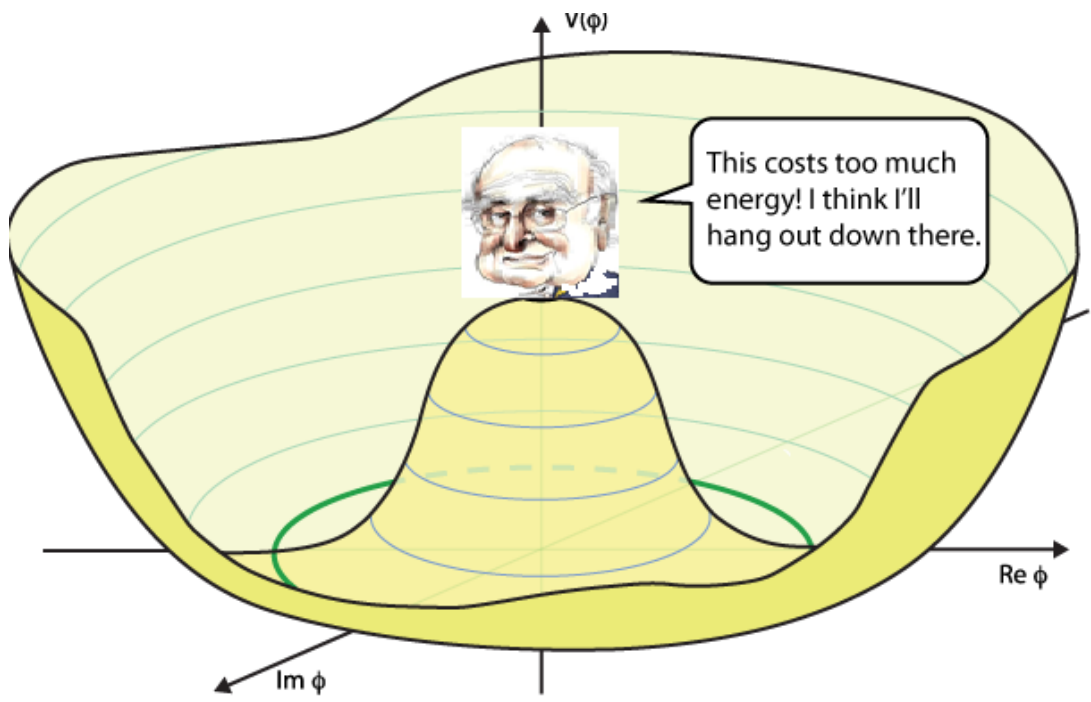

Fig.6 The Higgs Boson on the Potential Hill (Symmetry maintained)

The Higgs Field consists of two parts. The first part is the dynamic field whose quanta are the Higgs Boson and the second part is a constant called the 'Vacuum Expectation Value'. In Quantum Field Theory, the coupling of the Higgs Field to other fields is interpreted as giving mass to those fields. The coupling happens only when the symmetry is broken.

The essence of the Higgs Mechanism is the breaking of symmetry. The potential energy function of the Higgs Field as explained in the previous rigorous mathematical treatment looks like a Mexican Hat which is shown comically in Fig.6. The object on the potential hill is a caricature of Peter Higgs. Well !, readers, I have not made the outstanding physicist of our time and the world renown physicist, Peter Higgs a clown by showing him sitting on the potential hill in the figure. In fact, as a simple author, I would like to credit him by re-naming the Big Bang as Higgs Bang. There is no personal attack on Peter Higgs because the picture is not Peter Higgs. It is a caricature.

As all physical systems would like to be in the ground state of minimum energy, the Higgs Boson rolls down the hill and occupies the ground state. This is shown in the next Fig. 7. As far as the Higgs Boson is on the top of the potential hill, a symmetry is maintained because any rotation will not affect the position of the boson akin to the poles of Earth remaining stationary in its rotation. But the moment it rolls down abruptly, the symmetry is broken and this happens spontaneously and hence called 'Spontaneous Symmetry Breaking'. In the position of broken symmetry, any rotation of the potential field as per direction shown by the thick arrow (Fig.7) the field will not remain in the same p[lace. In the language of Quantum Field Theory, when the boson rolls down and occupies the lowest energy state, we say that it acquired a Vacuum Expectation Value which is the value of the field at that level. During the interaction of Higgs Field with other fields, there arises some interaction terms looking like this:

$$
\mathrm{g} \bar{\psi} \psi \phi
$$

where $\phi$ is the Higgs Field, $\bar{\psi}$ and $\psi$ are fields of some particle and its anti-particle for example, an electron and a positron. $g$ is just a number, called the coupling constant which determines the strength of the interaction between the three fields (electron, positron and Higgs).

Now, let us denote the Vacuum Expectation Value as $\mathrm{v}$ which is just a number. The Higgs field now becomes $\phi=$ New field $\mathrm{H}+$ Vacuum Expectation Value. That is,

$$
\Phi=\mathrm{H}+\mathrm{v} \ldots \ldots \ldots \ldots \ldots
$$

Hence g $\bar{\psi} \psi \phi$ now becomes

$$
\mathrm{g} \bar{\psi} \psi \phi=\mathrm{g} \bar{\psi} \psi \mathrm{v}+\mathrm{g} \bar{\psi} \psi \mathrm{H}
$$

where we have replaced $\Phi$ with the Higgs boson. 


\section{International Advanced Research Journal in Science, Engineering and Technology}

Vol. 5, Issue 8, August 2018

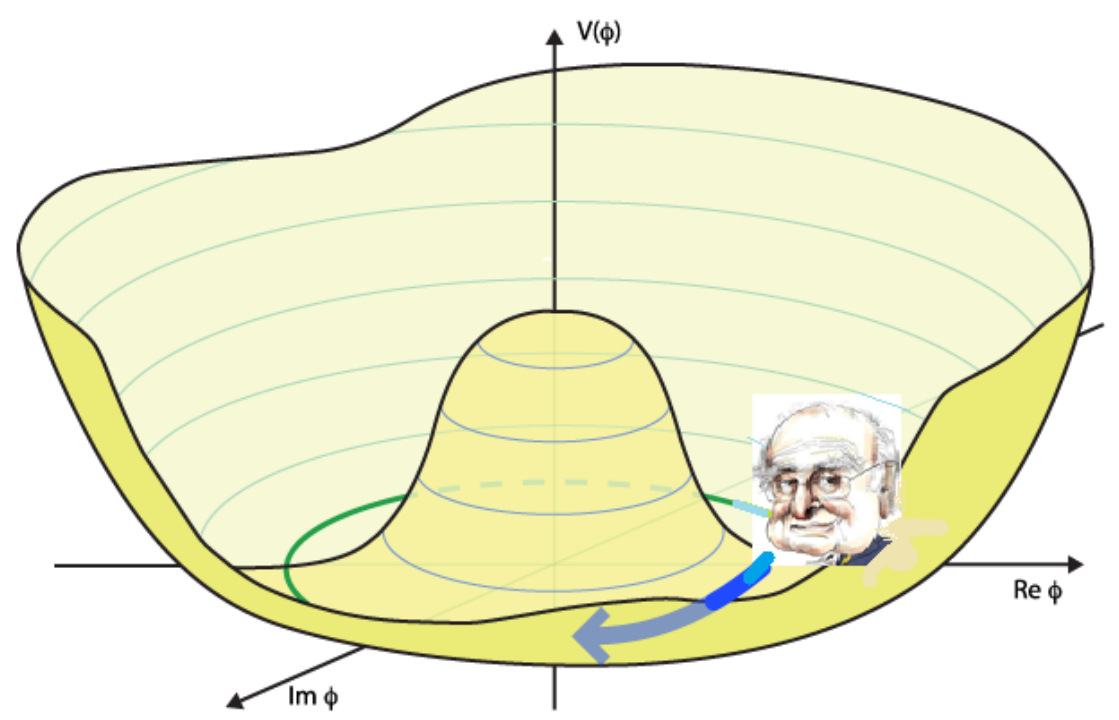

Fig.7The Higgs Boson down the Potential Hill (Broken Symmetry)

The expression on the left of (11) is where the mass comes from. First let us combine $\mathrm{v}$ and $\mathrm{g}$ together as they are both numbers and call it as $\mathrm{m}$, that $\mathrm{m}=\mathrm{g} \mathrm{v}$ and hence the expression becomes $\mathrm{m} \bar{\psi} \psi$. This is an 'interaction term' between a particle and its antiparticle and there is no third field. Such an interaction is called 'drum roll', a mass term. Thus, according to Quantum Field Theory, this term says that both the electrons and positrons have acquired mass $\mathrm{m}$ which they did not have it before. But, with the help of the Higgs Field's Vacuum Expectation Value, we have managed to create a mass term out of nothing. This is how the Higgs field gives mass to particles.

From the chart of Table No.4 there are 16 particles excluding the Higgs boson. Out of this only 12 particles get mass by Higgs mechanism. Other particles are composite particles such as a proton, for example, is made up of two $\mathrm{u}$-quarks and one d-quark. The quarks move inside the proton and gain kinetic energy and also bind together with binding energy. These energies together contribute for the mass of the proton.

Both the mathematical treatment and the treatment of Brian Greene appear to be trivial.

The theory of the Higgs boson and its field was first explicitly predicted and formulated in October 1964 by Peter Ware Higgs (b.1929...) and hence his name is associated with the particle. Robert Brout, Francois Englert, Gerald Guralnik, Carl Hagen and Thomas Kibble are some others who independently worked on the same topic and submitted their report in November 1964.

Martinus J.G. Veltman [6] says that creation of mass to other particles is something like other particles eating the Higgs boson to gain weight something like a blotting paper absorbing ink.

4.3.The Discovery: In scientific research specially in a subject like Physics, theory is one part and experimental verification of the theory is another part. The experiments to detect the Higgs boson which is the critical ingredient for the complete understanding of the Standard Model, failed in the Large Electron Positron (LEP) Collider at Geneva. What is required is a superconducting super collider so as to create a new strong reaction to achieve super symmetry. No theory, the General Theory of Relativity of Einstein or the Yukava theory of the Meson took the scientific community of the world to put to time and expense as the Large Hadron Collider (LHC) at Geneva. It took nearly half a century and the Golden Day was Wednesday, 4 July 2012 when it was detected in the Large Hadron Collider (LHC) at Geneva. In the words of Amir D Aczel [ ] (1950 - 2015) (Fig.8) an Israeli-born American lecturer in Mathematics and the author of 'Fermat's Last Theorem' and 'Present at the Creation' who was physically present at the creation of the particle:

I was fortunate to be invited by the CERN laboratory to visit the Large Hadron Collider. I saw the giant machine underground before the particle collisions began and was awed by its immense size and power. When the experiment began, I was there inside the control room of the entire operation, seeing what the scientists were observing on their computer screens, talking with scores of theoretical and experimental physicists, and experiencing the immensely exciting moments for science as new discoveries far beyond our imagination were being made.

"The immense research effort to find this elusive particle believed to give mass to the universe has involved the work of the world's most prominent theoretical physicists, including a number of Nobel Prize winners, leading mathematicians, and thousands of experimental physicists, engineers, technicians, and support staff. The project cost 


\title{
International Advanced Research Journal in Science, Engineering and Technology
}

\author{
Vol. 5, Issue 8, August 2018
}

well over $\$ 10$ billion and entailed building the greatest machine in the world and operating it continuously for years. At a 16.5-mile circumference, placed inside a tunnel buried 300 feet underground, stretching from the foothills of the Swiss Alps across the border to the rolling hills of the French Jura, the Large Hadron Collider is the biggest machine (Fig.9) ever built. It consumes the electric power required by a large city and uses it to generate energies never before seen - on the scale of atoms - since the Big Bang launched our universe 13.7 billion years ago."

The experiment to find the Higgs boson consisted of accelerating protons obtained from hydrogen gas through a series of smaller particle accelerators, and finally injecting them into the Large Hadron Collider, which propels them to more than 99.999 percent of the speed of light; then these particles crash head-on against others flying in the opposite direction, to see what new particles are created from the immense burst of energy that results from the collisions. As announced on Wednesday, July 4, 2012, the Higgs boson was found to be created in these gargantuan explosions of energy. In Fig.10 is shown Peter Higgs standing inside the LHC and in Fig.11 the collision.

Alan Walker [1] mentions that Maxwell's work took the electric and magnetic forces and unified them into one single electromagnetic field. Peter Higgs contribution was crucial in helping others in unifying the electromagnetic and weak forces. At 3 PM on Tuesday, 8 October 2013 Peter Higgs was informed of his Nobel Prize sharing with Belgium physicist, Francois Englert.

Before the discovery, Michael Chanowitz [8], the theoretical physicist in his paper titled. "What if there is no Higgs Boson?", says: "Without understanding the origin of mass, the theory of fundamental particles is not only incomplete, but is truly nonsensical, because it predicts that certain process occur with probability > 100\%. The Higgs Mechanism eliminates this nonsense from the theory at the same time that it explains how mass is acquired. But the nonsensical prediction of the incomplete theory is actually very useful, because it allows us to determine the energy and the collision rate needed by a particle accelerator to discover the true nature of the Higgs Mechanism".

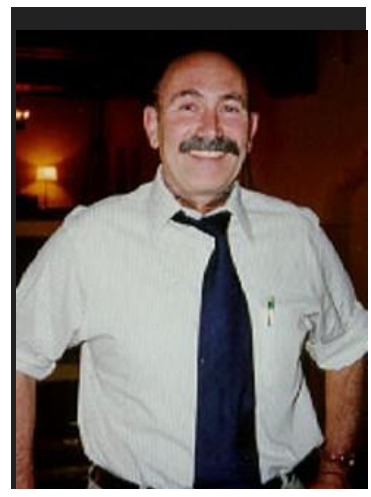

Fig.8 Amir D. Aczel (1950-2015)

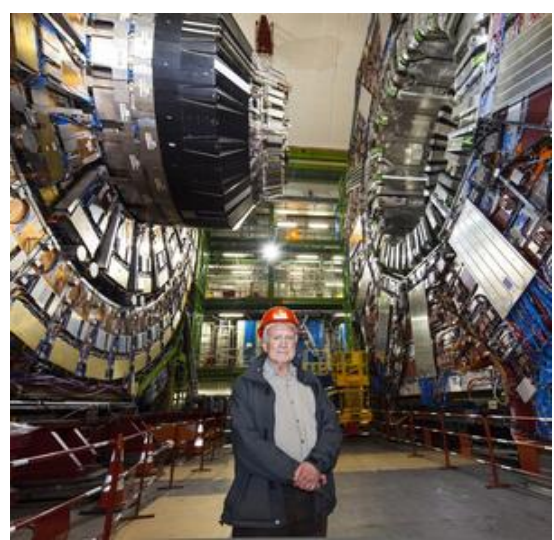

Fig.10 Peter Higgs in front of the Giant Machine

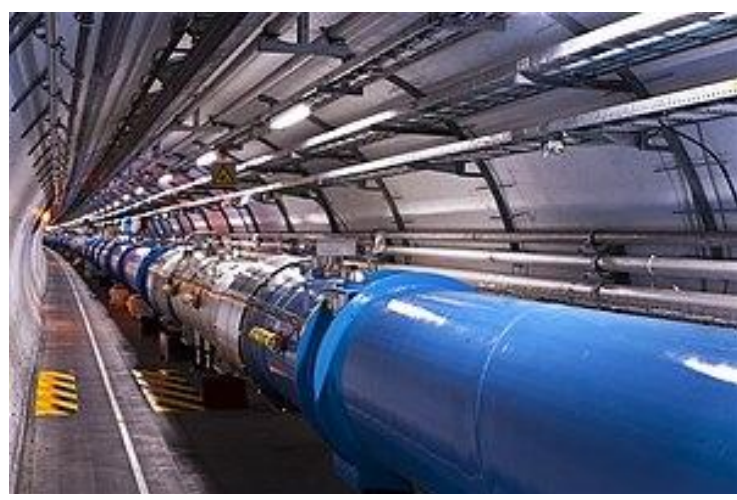

Fig.9 A side view of the Large Hadron Collider (LHC)

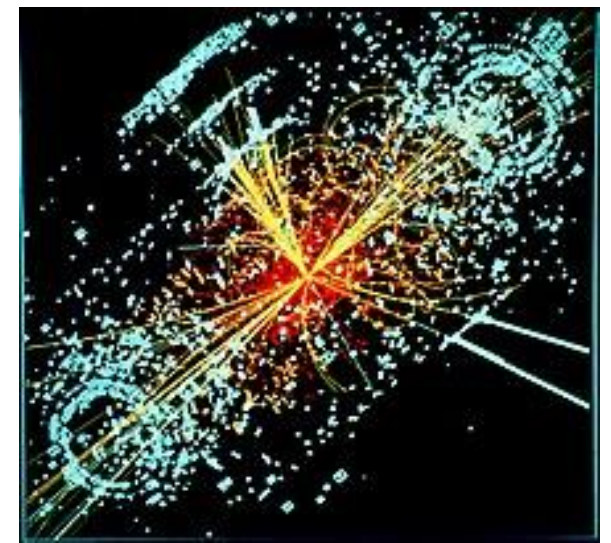

Fig.11 The Collision

Physicists working at the Large Hadron Collider have made a major new detection of the famous Higgs boson, this time catching details on a rare interaction with one of the heaviest fundamental particles known to physics - the top quark (Fig.12 ). Top quark also known as the t-quark or truth quark is the most massive of all the observed elementary particles. It is a Fermion with spin $\frac{1}{2}$ and experiences all 4 fundamental interactions gravitation, electromagnetism, weak interactions and strong interactions. 
Vol. 5, Issue 8, August 2018

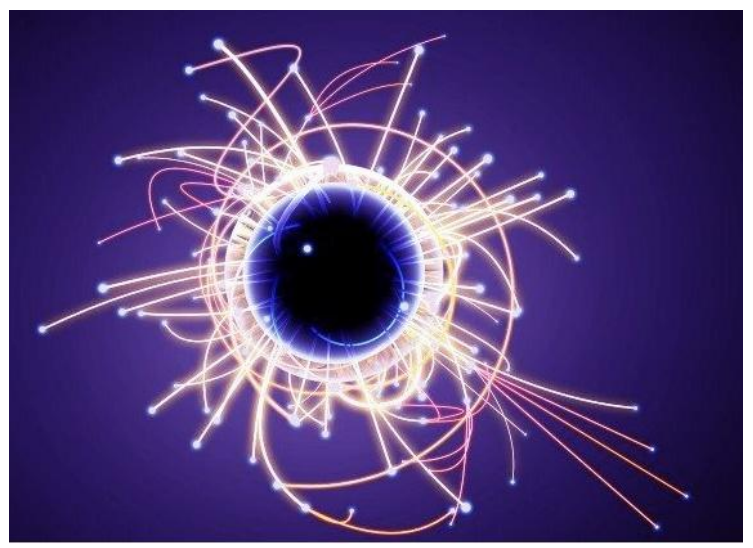

Fig.12 Illustrating the interaction of Top quarks producing Higgs Boson (13) and (14)

Feynman diagrams for production of Higgs boson and its interaction with other particles are shown in Figures

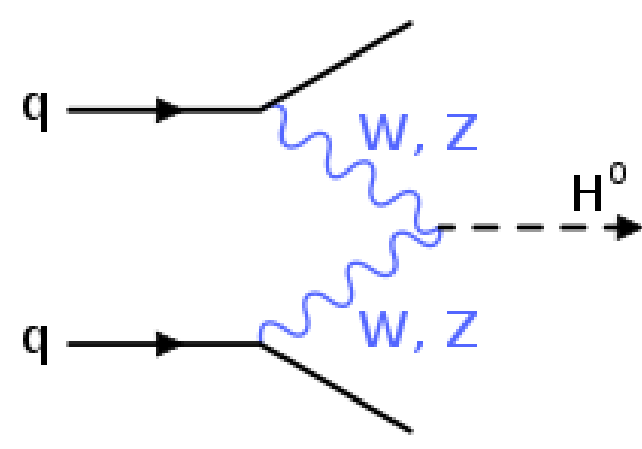

(a)Via quark and $\mathrm{W}$ or $\mathrm{Z}$ bosons

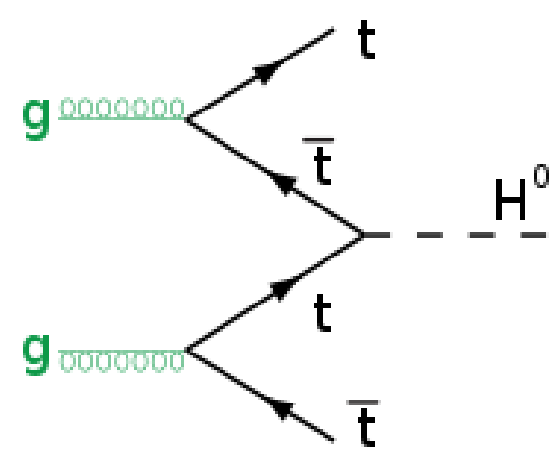

(b) Via gluons and top quarks

Fig.13 Feynman diagrams for Higgs boson production

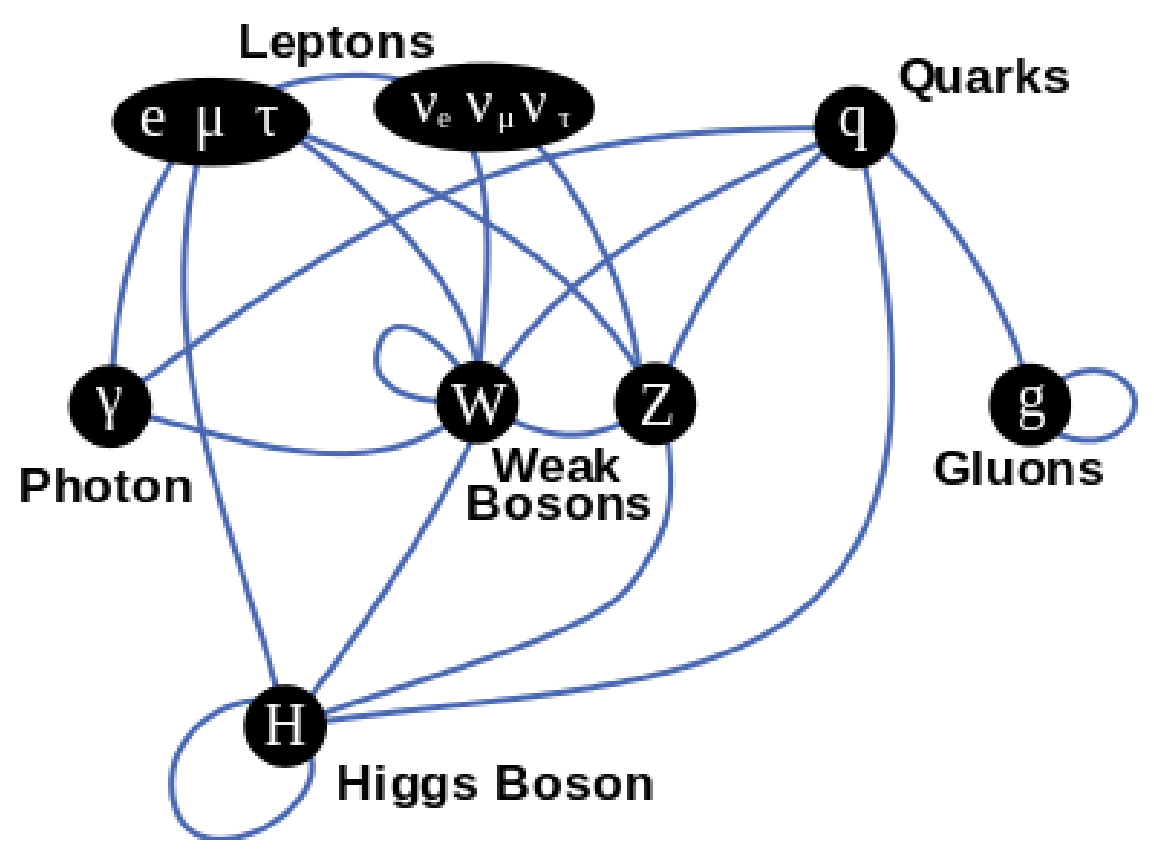

Fig14.Simulated Large Hadron Collider CMS particle detector data depicting a Higgs boson produced by colliding protons decaying into hadron jets and electrons 


\title{
International Advanced Research Journal in Science, Engineering and Technology
}

\author{
Vol. 5, Issue 8, August 2018
}

\section{CONCLUSION}

My paper has become very extensive and exhaustive and ran into pages. Looking Back to the title, "Plato to Peter Higgs", which has given an overall coverage of the subject involving all topics from the ancient times to the present, a specific topic such as 'Mechanics' has been developed by none other than Archimedes, who invented the lever and screw and further developed by Newton. Hence, it is "Archimedes to Newton". For 'Gravitation', it is "Galileo to Einstein". For 'Optics', it is "Alhazen to Isaac Newton" or even Thomas Young" For 'Particle Physics' starting from electron, coming to the Quarks or the Boson, we may put "J.J. Thomson to Murray Gell-Man" or "J.J. Thomson to Peter Higgs". Now, coming to Quantum Mechanics, we can say, "Max Planck to Heisenberg" and so on.

\section{ACKNOWLEDGEMENT}

It is the 'History' and 'Philosophy' of Physics we have been dealing with. Philosophy can be changed or put in different ways by different authors and impress the readers. But, however, when we come to the history of Physics or for that matter, history of anything, we have to necessarily depend on the writings of others. This has been systematically given with complete coverage by the well-known International Website, "Wikipedia". Most of the matter, specially the pictures of scientists and their biographies are from that. This, I am writing with sincere thanks to Wikipedia and acknowledge the same to all readers through this paper.

\section{EPILOGUE}

Looking upon the overall developments in Physics, I consider the splitting of the atom and the discovery of the Higgs boson as the most outstanding discoveries of the $20^{\text {th }}-21^{\text {st }}$ century. Electrons can be easily knocked out of atoms by processes known as ionization, but cracking the nucleus, the very kernel of the atom as done by Hahn and Strassman in the process of nuclear fission which, later on, led to the making of the bomb, as a major part of the Manhattan Project, that destroyed Hiroshima and Nagasaki that brought the world to sorrow. But, the physicists world over, at least in their minds were, in a way, happy over the confirmation of the success of Einstein's equation of massenergy equivalence, $\mathrm{E}=\mathrm{m} \mathrm{c}^{2}$. The starting point for both the joy and sorrow dates back to 2 December 1942 at a place named Stagg Field in the University of Chicago by Enrico Fermi and his team of physicists successfully achieved the

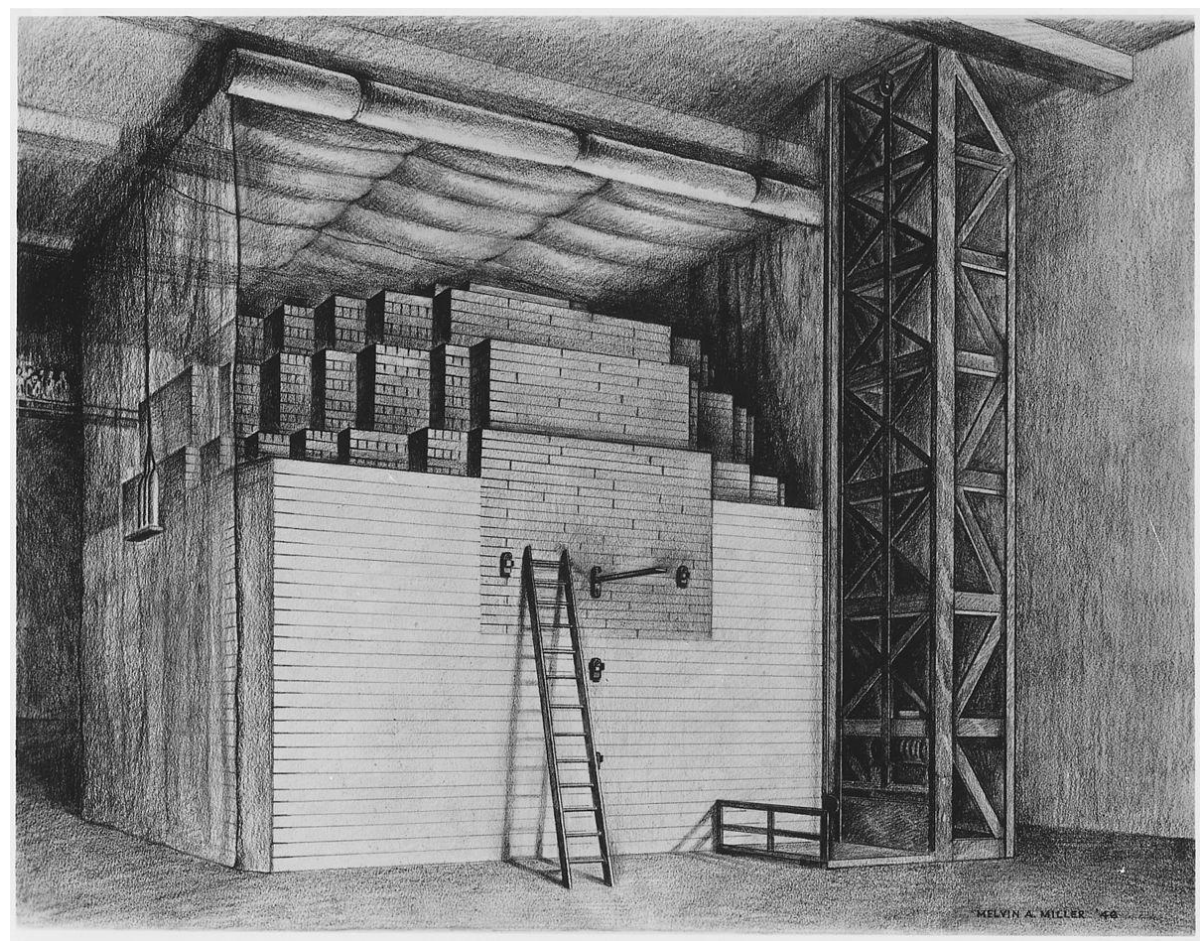

Fig.15 World's first Nuclear Reactor at Stagg Field, University of Chicago 


\title{
International Advanced Research Journal in Science, Engineering and Technology
}

\author{
Vol. 5, Issue 8, August 2018
}

world's first controlled nuclear reaction in the Pile-1 (Fig.15) which has been recently dismantled and a monument is erected in its place depicting the nuclear explosion of the Hiroshima bomb on 6 August 1945. As a physicist, I consider the place revered of historical and scientific importance and decided to go and see the same like a pilgrimage.

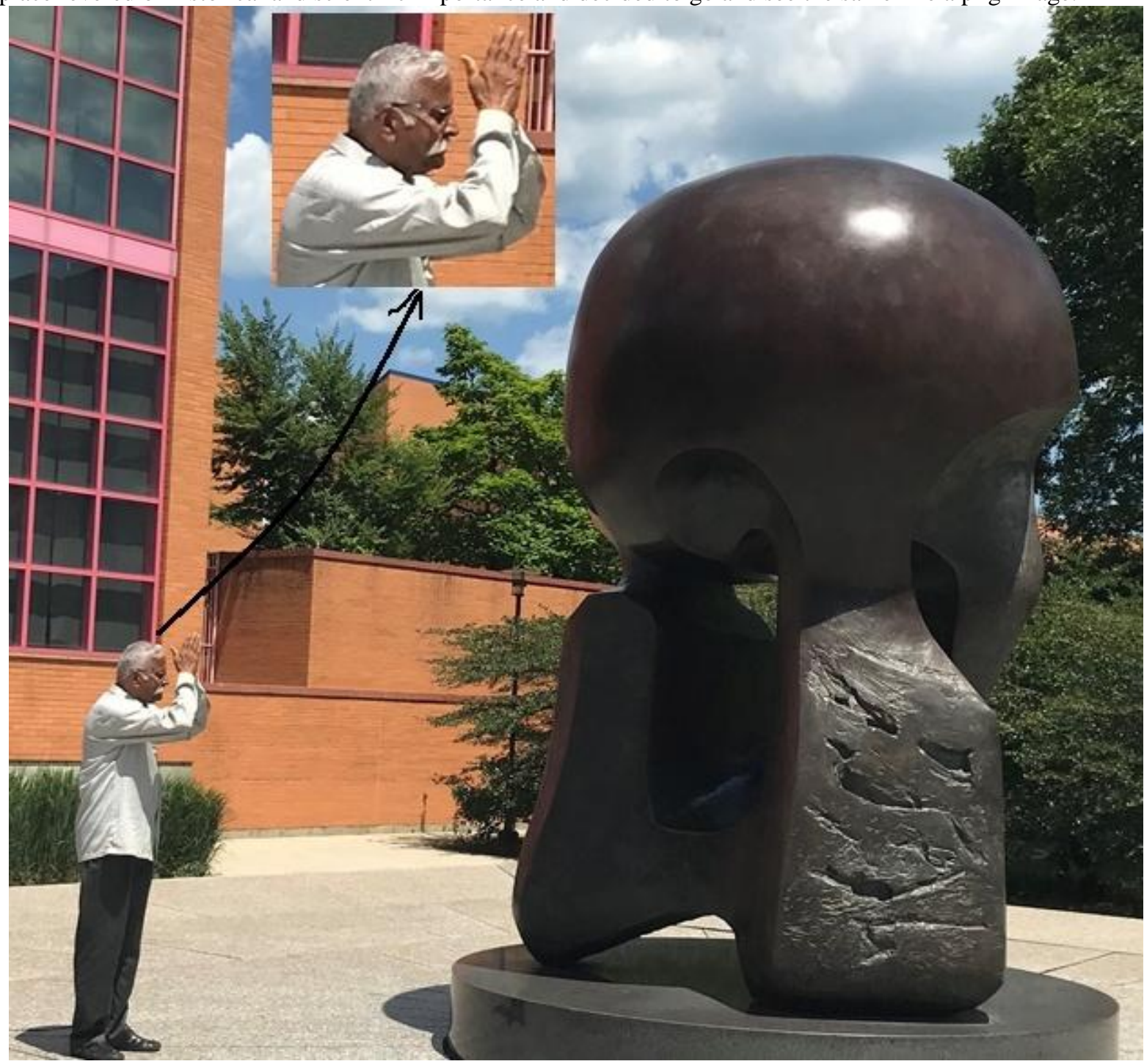

Fig.16 Dr. V.C.A. Nair, author of this Paper in a posture of worship close to the metal replica of the first Mushroom of the Hiroshima explosion of 6 August 1945 installed at the very place where the Pile-1 of Enrico Fermi and his team went critical on 2 December 1942 at the Stagg Field, University of Chicago.

Thursday, 26 July 2018

I did it on Thursday the $26^{\text {th }}$ July 2018. I started by Air from my residence at Foster City, San Francisco, CA, USA94404 on Wednesday the $25^{\text {th }}$ July 2018 and reached Chicago the next day, Thursday the $26^{\text {th }}$ and straight away went to the place and stood in reverence with folded hands as if in front of a deity (Fig.16) Just opposite the replica is a metallic plaque with a caption as shown in (Fig.17)

The second outstanding discovery, according to me, is the discovery on 4 July 2012 of the Higgs Boson, the socalled God's particle even though there is nothing divine about it. Peter Higgs himself is not in support of calling it so. But, the particle is responsible for life in the universe. I would like to pose a

simple question to readers whom I suppose to be physicists: "Is not the Higgs boson responsible for the principle of conservation of mass and energy?" Better change it to as "The Principle of creation of mass and energy" 


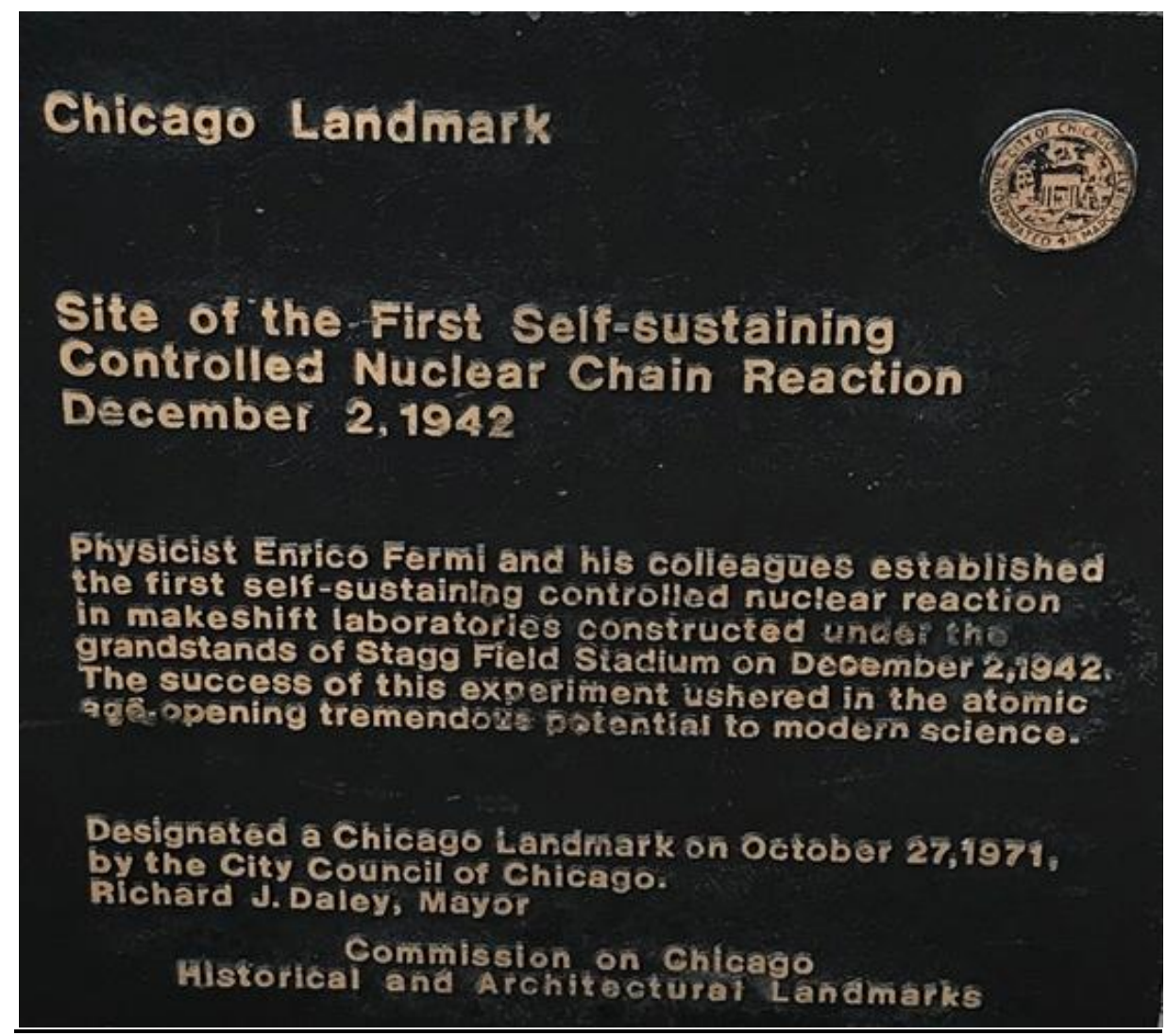

Fig.17 The Plaque opposite to Fig.16

\section{REFERENCES}

[1]. Alan Walker, "From Maxwell to Higgs", University of Edinburgh News letter of the James Clerk Foundation, Issue No.4, Spring 2014.

[2]. Amir D. Aczel, A well known Israeli-born American author and lecturer in history of Mathematics and Science, "Present at the Creation" Standard Model

[3]. Brian Randolph Greene, American Theoretical Physicist and Professor of Mathematics at Columbia University, US

[4]. Chris Quigg, Scientific American

[5]. Hypertextbook, Physics, Standard Model

[6]. Martinus J.G. Veltman, "The Higgs Model”, Scientific American, 1986, p.76-84

[7]. Math Pages, "On the Higgs Mechanism

[8]. Michael Chanowitz, "What if there is no Higgs Boson?"30-11-2011

[9]. Mike Mcrae, A freelance writer, 6 June 2018

[10]. Nair VCA, "Measurements Ten and Now" International Journal of Innovative Research in Science and Technology"p.19121.

[11]. Wikipedia

\section{BIOGRAPHY}

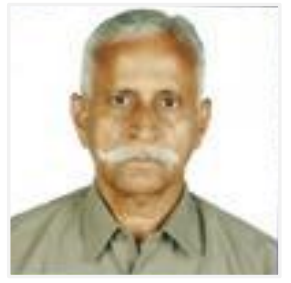

*Dr.(Prof.) V.C.A. Nair (b.15th Aug. 1939) is an Educational Physicist, Counselor, Research Guide and Consultant. He did his Masters in Physics from Mumbai University, India and Ph.D. from JJT University, Rajasthan also in India He is a Research Guide and distinguished alumni of JJT University. He is also a Chancellor designated Resource Person in the area of Physics in the University. He has to his credit over 4 decades of teaching Applied Physics in eminent Polytechnics in Mumbai and having taught nearly 16,000 students since 1965. He has published a number of research papers in Physics and Geophysics in International and UGC recognized Journals some of which can be seen in the net 'Google Search' when the name of the author or his e-mail is typed in that style. He is a Life Member of Indian Society for Technical Education which is an all India body. He had been to USA a number of times and visited eminent Universities such as Stanford, Harvard, MIT, 3 Universities of California at Berkeley, Los Angeles and also at Davis, University of Princeton at New Jersey, University of Chicago and University of San Francisco. At present Dr. Nair is a Research Guide for Physics at JJT University, Rajasthan-333001, India. He is member of the Editorial Board of this Journal. His Ph.D. Thesis is in Geophysics and he is working on topics such as Tides, Clouds, Global Warming and Climate Change. - Editor.

*nairvca39@gmail.com. 